\title{
2002 MRS Spring Meeting Integrates Soft Materials with Traditional Research
}

More than 2400 scientists gathered at the 2002 Materials Research Society Spring Meeting, held April 1-5 at the San Francisco Marriott and Argent Hotels in San Francisco. Along with the 23 technical symposia, meeting chairs Zhenan Bao (Bell Laboratories/Lucent Technologies), Eugene A. Fitzgerald (Massachusetts Institute of Technology), Ulrich M. Gösele (Max Planck Institute for Microstructure Physics, Halle), and Kenneth P. Rodbell (IBM T.J. Watson Research Center) treated attendees to special events covering homeland security, venture capital-getting science to the marketplace, and, most popular, the history of wine. At the plenary session on Wednesday evening, J. Hendrik Schön (Lucent Technologies) received the Outstanding Young Investigator Award and Jeff Wadsworth (Lawrence Livermore National Laboratory) gave the plenary address on science and technology and counterterrorism.

Organic materials and biological connections are increasingly integrating into the mix of rapidly developing areas in materials research. In addition to the common strength in electronic and optoelectronic materials, the meeting included a cluster of five symposia on molecular and biomaterials, along with coverage of flexible substrates for electronics, polymer nanocomposites, and bioMEMS. Areas such as microfluidics rely on MEMS technologies to interface with biological-scale flow. Organics are leading to low-cost, large-area electronics and photovoltaics as functionally useful materials that can be processed inexpensively. And while materials research has not made a major course change following the September 11 attacks, several special sessions relating to security and counterterrorism point to the materials challenges of biosensors.

\section{Electronic and Optoelectronic Materials}

Symposium D on perovskite materials represented the interdisciplinarity that is the hallmark of MRS meetings and symposia. To an audience of materials scientists, R. Jeanloz (UC-Berkeley) gave an earth scientist's perspective on perovskite materials as he discussed the properties of silicate perovskites relevant to the earth's mantle. To simulate the high pressures found in the earth's interior, diamond anvil cells are used along with facilities such as synchrotron radiation sources. Jeanloz said that $(\mathrm{Mg}, \mathrm{Fe}) \mathrm{SiO}_{3}$ perovskite makes up $70-90 \%$ of the deep mantle, which corresponds to $40 \%$ of the planet. While the deep mantle cannot be directly sampled, acoustic measurements during earthquakes, for example, provide a great deal of information about its composition and structure.

Several talks within Symposium E focused on nanostructural magnetic materials for data storage. One was by K. Krishnan (Univ. of Washington) on assembly techniques and shape control of Co nanocrystals, as they are being touted as a potential data-storage material. Co nanocrystals were synthesized by the injection of a precursor into hot coordinating solvent followed by growth. The nanocrystal shape was controlled by the use of several coordinating ligands that bind preferentially to different faces of the nanocrystal, allowing different faces to grow at different rates to produce nanorods of controlled lengths and thicknesses. Assembly of the magnetic nanocrystals is accomplished by the controlled addition of a nonsolvent to a solution of nanocrystals, allowing the uniform deposition of a monolayer. Krishnan said that the packing pattern of spherical nanocrystals can be controlled by controlling the nanocrystal size, and the packing patterns in nanorods are just beginning to be studied.

In the same symposium, K. Hanif (UCSB) presented a study of electron-spin interactions and magnetic behavior in Codoped CdSe nanocrystals. The study of electronic and magnetic properties of quantized systems is of great interest, considering the continuing miniaturization of electronic and magnetic data-storage components. Nanocrystals $5.5 \mathrm{~nm}$ in diameter with doping levels of $0.04-0.30 \%$ Co were prepared by controlled decomposition of single-source precursor clusters in a coor- dinating solvent. The doping level was measured by elemental analysis. A uniform distribution of dopant atoms in the CdSe core was confirmed by Vegard's law, which correlates lattice-spacing changes, measured by XRD, with Co doping levels. This previously unreported uniform Co distribution in CdSe nanocrystals made these materials an excellent system to study spin-spin interactions, Hanif said. Nanocrystals with all doping levels exhibited a paramagnetic-to-antiferromagnetic behavior transition at $\sim 4 \mathrm{~K}$; this occurred at $<1 \mathrm{~K}$ in the bulk system. Hanif said that the transition occurred at a higher temperature for more extensively doped materials because of more prevalent Co-Co interactions. These extended interactions arise from changes in the radial extent of the Co spin interaction, which is found to be 20 times larger than that observed in the bulk system. These results shed light on the effects of quantization on the magnetic behavior of semiconductor systems and the ability to control doping levels in quantum-confined materials.

Getting light out of silicon is generally difficult due to its indirect bandgap and the strong thermal quenching of the radiative transitions. However, in Symposium F, K.P. Homewood (Univ. of Surrey) said, "Silicon has an even brighter future," in reference to accomplishing such a feat. The primary challenge, he said, is to eliminate nonradiative recombination. Homewood summarized earlier work describing how efficient, room-temperature silicon LEDs can be realized by using entirely conventional ULSI technology. Implanted B was used to make efficient Si LEDs at room temperature. Heating used to reactivate and reorder the material leads to isolated silicon regions and dislocation loops that form barriers. Pinned electrons do not diffuse and thus have no choice but to recombine giving out light. Now $\beta-\mathrm{FeSi}_{2}$ is being studied which, combined with the dislocation technology, adds to the potential for Si-based optical detectors and solar cells.

Evident in Symposium G was how quickly research on materials for flexible electronic displays and devices is turning into technology applicable in a broad range from airport security to inventory. In separate presentations, H. Klauk (Infineon Technologies) and R. Stewart (Alien Technology) described their work on low-cost radio-frequency identification 
technology (RFID). Klauk said that current identification systems such as bar code systems can read only one label at a time. RFID may be a better replacement, he said, since it basically uses radio frequencies to exchange information between a tag-also called transponderand an interrogation device. The integration of RFIDs could revolutionize the retail system and supply chain, according to Stewart, whose company is in the process of bringing RFID tags to the market. The tags would lower retail costs and eliminate checkout lines as shopping could be conducted through home computers that automatically scan for RFID tags and order items as needed. Cost is currently the main barrier, at $\sim 10-15$ cents per label, while the goal is $<1$ cent per label. Stewart also talked about efforts to bring flexible displays to the market in such products as smart-card displays.

G. Bryan-Brown (ZBD Displays Ltd.) introduced technology for flexible LCDs for rugged image storage. Instead of using supertwisted nematic or activematrix twisted nematic technologies, which dominate current LCD products, it is based on zenithal bistable display (ZBD) technology. A ZBD is a bistable nematic LCD that relies on surface rather than bulk bistability and can retain a written image after the application of mechanical shock. The liquid crystal sits between an embossed asymmetric grating and a rubbed polymer surface. Pixels are switched on with the voltage on, and then the voltage is turned off. BryanBrown reported that a black and white $160 \times 160$ pixel matrix-addressed ZBD prototype has been made which shows good $(33 \%)$ reflectivity and 15:1 contrast. It can be flexed and compressed without loss of the written image. These devices have ultralow power consumption, he said, because power goes off except when updating the image. Furthermore, ZBD technology is fully compatible with web roll-to-roll processing.

The first products based on research of photonic-crystal fibers are also beginning to emerge, as presented by P. St.J. Russell (Univ. of Bath) in Symposium L. A photoniccrystal fiber consists of a thin thread of silica glass of essentially unlimited length (easily several $\mathrm{km}$ ) with a parallel array of microscopic air channels running along it. The diameter of the channels (or holes) can range anywhere between $\sim 25 \mathrm{~nm}$ and $\sim 50 \mu \mathrm{m}$. Guiding cores are created by filling in or enlarging individual air channels. Russell recapped work showing an endlessly single-mode structure that sieves away higher order guided modes as the light propagates. Birefringent fibers and square-lattice photonic-crystal fibers with, for example, four cores running down its length, can be made as well as hollow-core photonic bandgap fibers with potential for communications. Other designs, such as the "grapefruit" fiber, in which the cross section looks like that of a grapefruit and the core is only $1 \mu \mathrm{m}$ across, can be used to control chromatic dispersion. Russell also mentioned the sunlight laser, which produces light with the bandwidth of the sun but 10,000 times brighter. He said, "Microstructuring transforms optical fiber from a mundane commodity into an almost magical new material, full of new effects and useful in a host of applications from high-power lasers to telecommunication."

\section{Molecular and Biomaterials}

Advancements in biomaterials traditionally relied on the implantation of materials foreign to the body. Presentations in Symposium $\mathbf{N}$ showed a movement to the use of organic-inorganic hybrid materials to guide biological systems. In B.D. Ratner's (Univ. of Washington) presentation on biorecognition strategies for improved biomaterials, Ratner said that all biomaterials that are currently implanted in living tissue are basically walled off from the body in a collagen bag. This can degrade the performance for the bioimplants. On the other hand, the body heals wounds through specific reactions, and it is useful to try to mimic these, he said, and he followed with several strategies. He discussed surface modification to turn on some reactions and turn off others. He said "stealth" techniques could also be used, wherein the body does not realize the presence of an implant. These are based on protein interactions. Ratner reiterated that the present

\section{ACRONYM KEY}

2D: two dimensional

3D: three dimensional

AFB: Air Force Base

AFM: atomic force microscopy

ALD: atomic layer deposition

ANL: Argonne National Laboratory

ARL: U.S. Army Research Laboratories

BST: barium strontium titanate

CMOS: complementary metal oxide semiconductor

CMP: chemical-mechanical polishing

CMU: Carnegie Mellon University

CNRS: Centre National de la Recherche Scientifique

DARPA: Defense Advanced Research Projects Agency

FEM: field emission microscopy

FET: field-effect transistor

FIB: focused ion beam

FTIR: Fourier transform infrared

HP: Hewlett-Packard

IC: integrated circuit
I-V: current versus voltage

ILD: interlayer dielectrics

IIT: Indian Institute of Technology

LCD: liquid-crystal display

LED: light-emitting diode

MD: molecular dynamics

MEMS: microelectromechanical systems

MIT: Massachusetts Institute of Technology

MOSFET: metal oxide semiconductor field-effect transistor

MPI: Max Planck Institute

NASA: National Aeronautics and Space Administration

NCSU: North Carolina State University

NIST: National Institute of Standards and Technology

NMR: nuclear magnetic resonance

NREL: National Renewable Energy Laboratory

OLED: organic light-emitting diode

ORNL: Oak Ridge National Laboratory

OSU: The Ohio State University

OTFT: organic thin-film transistor
PGLA: poly(lactic-co-glycolic acid)

PNNL: Pacific Northwest National Laboratory

PPV: polyphenylene vinylene

PSU: The Pennsylvania State University

PV: photovoltaic

R\&D: research and development

SAM: self-assembled monolayer

SNL: Sandia National Laboratories

STEM: scanning transmission electron microscopy

TEM: transmission electron microscopy

TFT: thin-film transistor

UC: University of California

UCLA: University of California, Los Angeles

UCSB: University of California, Santa Barbara

ULSI: ultralarge-scale integration

VCSEL: vertical-cavity surface-emitting laser

XAS: x-ray absorption spectroscopy

XRD: $x$-ray diffraction

ZBD: zenithal bistable display 
field of biomaterials will be followed by tissue engineering which will then be followed by regenerative medicine, which is the ultimate goal.

In the same symposium, S.-W. Lee (Univ. of Texas at Austin) described how viruses can be used to organize semiconductors. ZnS particles were aligned using genetically engineered DNA phages, Lee said. The phage DNA was imbedded in a protein coat, and the end was equipped with a genetically altered peptide sequence. The altered sequence attaches selectively to certain surfaces, creating patterning for nanoparticle attachment. Nanoparticles, in this case, $\mathrm{ZnS}$, then bind at the end of the virus to form an array. The process is inexpensive and reversible, Lee said, and a variety of semiconducting nanoparticles can be assembled by this method.

The link between the sensors field and medical diagnostics is a traditionally strong one, which was underscored by many of the presentations in Symposium $\mathrm{O}$-in particular, those from the industrial contributors. In addition, much emphasis was placed on the detection of chemical and biological warfare agents and toxic materials, an area that has emerged as a critical component of the United States' homeland defense and counterterrorism efforts. Chemical and biological strategies to engineer selective interfaces, membranes, bilayers, and polymeric films were discussed extensively. The area of sample preparation and handling, in either liquid or gaseous matrices, was also covered.

In Symposium P, T. Jackson (PSU) summarized the development of electronics based on organic thin-film transistors. Jackson described the fabrication of pentacene-based organic thin-film transistors on flexible low-temperature polymeric substrates, with performances comparable to a-Si:H devices. Thin-film mobilities of $3 \mathrm{~cm}^{2} / \mathrm{V}$ s have been achieved. Using these devices, researchers have fabricated digital and analog circuits, active-matrixdisplay pixel arrays, and integrated OTFT, that is, OLED active pixels. Controlling morphology still remains a challenge, he said, although defects are not as much of a problem as in the past.

In the same symposium, Z. Bao (Lucent Technologies) addressed molecular-scale organic transistors based on self-assembly. Self-assembly chemistry is very important for nanoscale electronic devices, she said. The major challenges are the nanoscale channels in the devices and the good contacts needed to be made to the molecules. Bao and her colleagues used conjugated dithiol as the self-assembling monolayer (SAM) to separate the source and drain

\section{Women in MSE Breakfast Hosts Panel on Alternative Careers}

"Alternative career" is a misnomer, according to the panelists who presented their stories at the Women in Materials Science and Engineering Breakfast early Thursday morning. Panelists Kelly Kirkpatrick, moderator and VC consultant in nanotechnology; Peter Fiske, entrepreneur and author on alternative careers; Betsy Fleischer, MRS Bulletin editor; Gail Oare, MRS director of Membership Affairs; and Eric Werwa, the current Materials Research Society/ Optical Society of America Science and Engineering Congressional Fellow addressed their non-laboratory careers.

The panelists emphasized that materials scientists with $\mathrm{PhD}$ degrees are trained to do bench science and have a myriad of writing, problem-solving, and communication skills that they developed during their educational experience. Charting a path outside of the laboratory requires individuals to have a solid understanding of what drives their intellectual, personal, and professional passions.

The panelists agree that career development is a lifelong process. On choosing a career, Fleischer's advice is to "do what you love, seize opportunities, and be persistent."

Fiske's advice is to network, "because people hire you for jobs, and are the ones who can let you know about jobs."

The MRS Public Outreach Subcommittee and the American Chemical Society (Inorganic Chemistry Division) co-sponsored the Alternative Careers in Materials Science Panel.

electrodes. The gate was still inorganic $\mathrm{SiO}_{2}$ on $\mathrm{Si}$. While this device was a vertical molecular-scale transistor, Bao also described some work with horizontal molecular-scale devices, which behaved similarly to the vertical ones. Bao also discussed an allmolecular-scale transistor, wherein the gate insulators are also a SAM with a thickness of $\sim 2.5 \mathrm{~nm}$. The future for SAMbased molecular electronics is very bright, she said, although a lot of work remains in the morphology of SAMs at the edges, the increased device yield, and understanding the operation mechanism.

In Symposium Q, P. Gomez-Romero (Instituto de Ciencia de Materiales de Barcelona, CSIC) presented a talk on hybrid organic-inorganic electroactive materials. Combining conducting organic polymers with active inorganic species (both extended and molecular) in nanocomposite materials could lead to synergy within the resulting nanocomposite materials for several applications such as energy storage and conversion. GomezRomero gave a historical background on conducting polymers and then discussed electroactivity and energy storage in some hybrid systems including polyaniline/

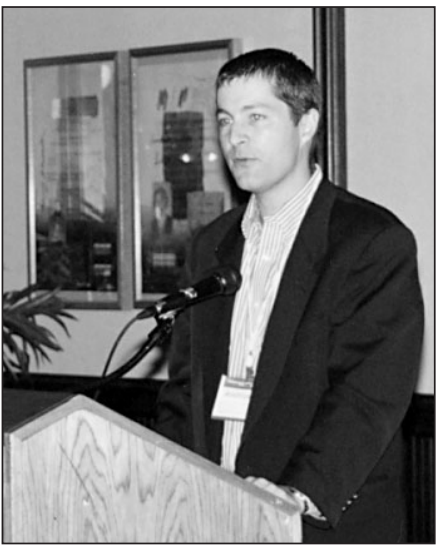

At the Women in Materials Science and Engineering Breakfast panel on alternative careers in materials science, panelist Peter Fiske, an entrepreneur and author, said there are really no "alternative" careers, but rather infinitely many career paths one might choose, some of them just might be "the walk less traveled."
$\mathrm{V}_{2} \mathrm{O}_{5}$ and polyaniline/hexacyanoferrate. These materials appear to be good candidates for positive electrodes in rechargeable plastic Li-ion batteries, he said.

\section{Nano-/Microstructured Materials and General Technical Topics}

Symposia R-U addressed materials modeling, nanostructured materials, polymer nanocomposites, MEMS and bioMEMS, and microfluidics. In one example, C.H. Ahn (Univ. of Cincinnati) presented his plastic "disposable smart biochip" that uses innovative structurally programmable microfluidic systems and plastic injection technologies. These biochips offer fast, reliable, and minimally invasive measurements of metabolic parameters from human blood. The principal biochip materials are cyclic olefin copolymers (COC).

In Symposium V, L. Kazmerski (NREL) gave an overview of PV R\&D. He said that first-generation PVs based on silicon and second-generation PVs based on thin films and concentrators continue to evolve in performance - most notably in efficiencywhile decreasing in cost. R\&D approaches to third- and fourth-generation PVs fea- 


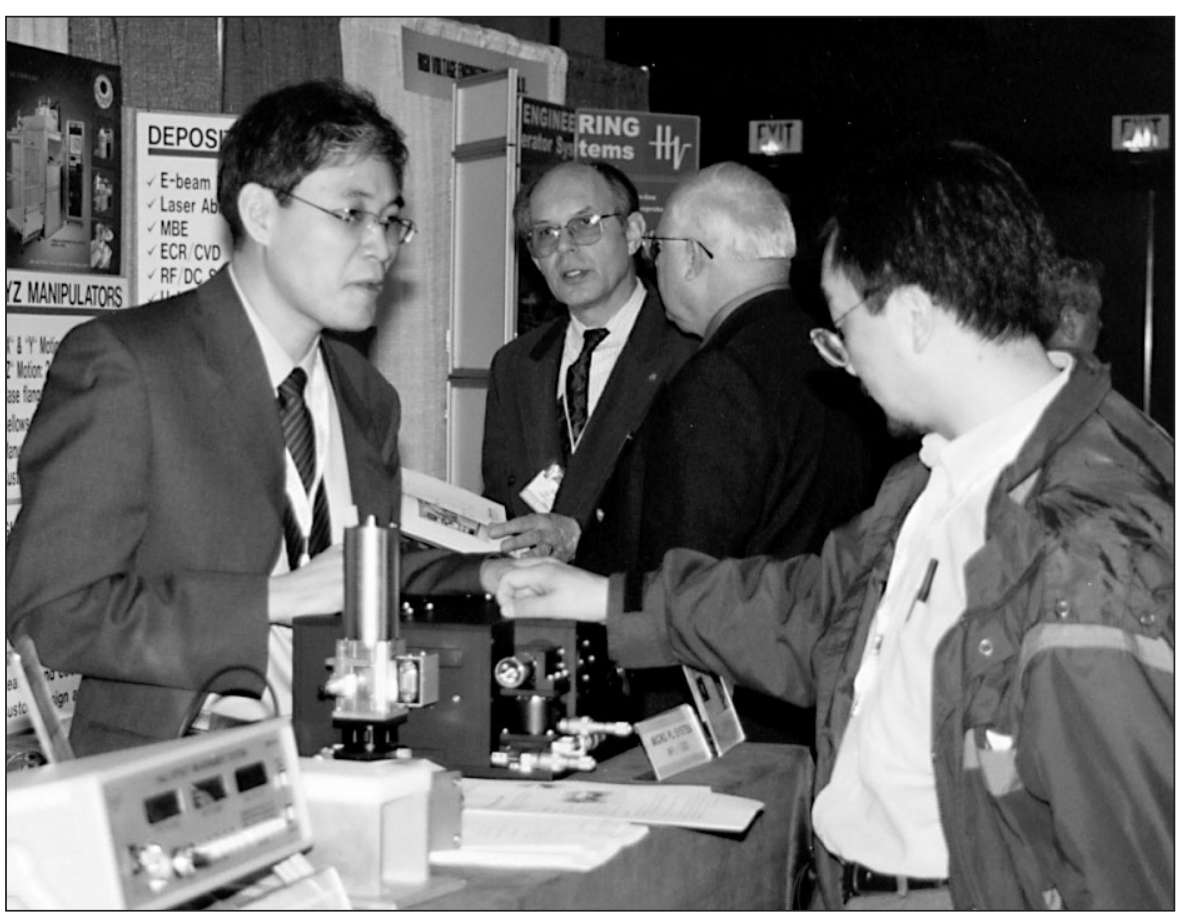

A meeting attendee interacts with a vendor in the Exhibit Hall where over 100 exhibitors showcased their products.

ture plastic solar cells (i.e., organic PVs), nanotechnology cells, multiple-junction thin polycrystalline films, and designer PV materials. Possible future applications include the integration of PVs into probes for biomedical diagnostics as well as the production of hydrogen directly from PVs.

For further details about the technical content of the meeting, read the following symposium summaries and see the published proceedings and MRS Web site updates (www.mrs.org).

\section{Amorphous Silicon Research Focuses on Growth and Degradation \\ (See MRS Proceedings Volume 715)}

Solar cells and imagers were strong themes of Symposium A on Amorphous and Heterogeneous Silicon-Based Films. Important areas of focus were increasing the deposition rate for a-Si:H cells and the development of higher efficiency microcrystalline Si solar cells. A research group from Jülich reported on a microcrystalline cell with an efficiency of $9.4 \%$ (unstabilized) and with an open circuit voltage of over $0.6 \mathrm{~V}$. A group from the National Renewable Energy Laboratory was able to increase the growth rate of a-Si:H cells fabricated using hot-wire deposition to 3-20 $\AA /$ s, while increasing the open circuit voltage to over $0.9 \mathrm{~V}$. Groups at United Solar Systems Corp. and PSU continued work on silicon materials in the transition region between amorphous and microcrystalline. A particularly intriguing result was presented by J. Yang (United Solar Systems) who found that the open circuit voltage of mixed-phase solar cells increased upon light-induced degradation.

Metastability and light-induced degradation continues to be an important area of study. NMR measurements revealed an associated reversible change in the hydrogen microstructure in a-Si:H. R.B. Wehrspohn (MPI, Halle) presented a refined model of degradation specifically constructed to meet the experimentally proven constraints on the hydrogen distribution.

There were lively sessions on growth mechanisms. The UCSB group described a molecular-dynamics simulation in which atomic hydrogen converted the a-Si network into an ordered c-Si lattice by inserting into bond center sites. J. Robertson identified a mechanism, previously eluding theory by which $\mathrm{SiH}_{3}$ radicals could bond to a $\mathrm{Si}: \mathrm{H}(111)$ surface. This seems to confirm the general belief that the $\mathrm{SiH}_{3}$ radical is central to film growth. It was also noted that the surfaces of a-Si:H must be very smooth to make good devices. M.C.M. van de Sanden (Eindhoven Univ. of Technology) showed how the surface roughness of a-Si:H gave information about the microscopic growth mechanism.

Microcrystalline Si is becoming the material of choice for display and imaging systems. J.P. Lu (Xerox PARC) gave a nice summary of the state of the art in this area.

Symposium Support: Akzo Nobel Chemicals $\mathcal{E}$ Shell Solar, Asahi Glass, BP Solarex, EPRI, Fuji, HP, MVSystems, NREL, Sanyo, United Solar Systems, Voltaix, and Xerox PARC.

\section{Silicon: How Much Farther Can It Go?} (See MRS Proceedings Volume 716)

Symposium B on Silicon MaterialsProcessing, Characterization, and Reliability, began with a tutorial on silicon processing. E. Levine (formerly of IBM, now with SONY), an industry expert, reviewed the problems and issues that occur in industrial fabrication facilities. These issues are faced by engineers worldwide, and have an impact on yield and manufacturability.

The presentations in the technical sessions reflected current concerns in technology advancement. Research in high- $\kappa$ dielectrics is in high demand because of the limitations in scaling of the industrystandard silicon dioxide. The stability of high- $\kappa$ films, control of interfaces, and interfacial oxides were active areas of discussion. Popular high- $\kappa$ dielectrics were zirconium oxide, hafnium oxide, aluminum oxide, strontium titanate, and yttrium silicate. Replacement of silicon dioxide with these high- $\kappa$ dielectrics is one method to allow for manufacture of transistors with characteristics of the next level of technology.

Bruce White of Motorola outlined an industry view of the technology roadmap with existing materials and new device designs. Results of a new dual gate MOSFET in silicon were presented, which demonstrated a near ideal subthreshold slope of $60 \mathrm{mV} /$ decade.

Exciting news in ALD for ILD applications was presented where growth rates of up to $120 \AA$ / cycle were obtained, which is an improvement of nearly 100 times in growth rate/cycle.

With the scaling reductions in die and device sizes, the processes used for metallization and interconnects must change to accommodate the smaller line widths and large aspect ratios of vias and interconnects. New silicidation research is providing information on new processes that manufacturers can apply to next-generation technology. Significant contributions were discussed in the advancement of silicidation and metallization, specifically, nickel silicides, and ongoing research for gate metals on $n$ - and $p$-MOSFETs.

The presentations on interconnects focused primarily on process integration of copper/oxide and copper/low- $\kappa$ interconnect structures, which are being actively developed by the semiconductor industry 
to replace the aluminum metallization. Presentations covered a wide range of subjects including low- $\kappa$ materials, characterization, processing, thin diffusion barriers, and reliability. These were highlighted by a presentation on local defect detection in IC interconnects, which introduced methods for finding failures in completed parts without having to de-process the part. These timesaving methodologies accelerate results of the failure analysis from weeks and months to minutes.

Symposium Support: MMR Technologies, Applied Materials, and Inorgtech.

\section{Ultrashallow Junctions Look Beyond Implantation}

(See MRS Proceedings Volume 717)

Symposium $C$ focused on the fabrication, characterization, and modeling of $p-n$ junctions for future silicon IC technologies. Implant and anneal cycles have served the industry for well over a decade, but the end of this process technology is in sight for ultrashallow junctions. Although implant energy can be reduced to very low values to form shallow junctions, it is difficult to get dopant activation high enough to meet the industry needs for shallow, low-resistance layers. Several alternate approaches were explored and discussed that can meet the industry requirements, including activation during solid-phase epitaxial regrowth, laser annealing that features substrate melting and recrystallization, flash lamp systems, and in situ doped epitaxial growth of raised source drain structures. The majority of the meeting focused on these possible future technologies. Many of the theoretical modeling talks discussed dopant activation and deactivation kinetics since supersaturated doping solutions

\section{U.S. Government Agencies Promote Funding Opportunities}

The 2002 MRS Spring Meeting presented three seminars highlighting materials research funding opportunities in the U.S. Office of Naval Research (ONR), the U.S. Department of Commerce's National Institute of Standards and Technology (NIST), and the U.S. National Science Foundation (NSF). This ongoing series within MRS meetings began a few years ago when funding officers at NSF realized that materials researchers knew very little about the grants available. Tom Weber, director of the Division of Materials Research at NSF, and Lance Haworth, executive officer of the division, updated the audience in the agency's 9th appearance at the MRS meetings, including opportunities for international projects co-funded by agencies in other countries. Education is a fundamental element to projects funded by NSF. Throughout their presentations, the officers directed the audience to the NSF Web site www.nsf.gov.

For the first appearance of ONR at an MRS Meeting, Julie Christodoulou, a program officer in the Materials Division, introduced areas within materials research that are currently being funded by the U.S. navy. The hierarchy she described at ONR consists of the chief naval officer and a civilian technical director at the top. The most relevant to materials researchers is the engineering materials and physical science department, designation 33. Closely related subdivisions include the materials division (332), headed by Robert Pohanka, and the physical science division (331), headed by John Pazik. Unlike NSF, ONR-funded research is not driven by scientific curiosities, but on the basis of need. The typical size of the university-level 6.1 (basic research) grant is $\$ 200-\$ 300$ thousand a year. Current areas of interest include those directed toward naval materials: ultralight-weight materials, materials and joining technologies for ship and submarine hulls and structures, advanced dielectrics for energy storage, and piezoelectric materials; as well as efforts to reduce maintenance: corrosion control, wear-resistant materials and coatings, thermal barrier coatings, and nondestructive testing techniques. Individuals and groups interested in soliciting ONR funding were directed to speak with the program officers in charge of these areas of specialization, who were identified during the seminar. More detailed and up-to-date information is available on the ONR Web site: www.onr.navy. mil and www.onrifo.navy.mil.

NIST held a session on its Advanced Technology Program (ATP), which is positioned to help technology-driven firms of all sizes to bridge the gap between the research laboratory and the marketplace, which the funding officers refer to as "the valley of death." The program is not designed to fund incremental advancements or product development, but instead cost-sharing awards are designed to help companies pursue pathbreaking new technologies that have been deemed too risky for conventional funding, but show potential for widespread benefits to the United States. Donald Bansleben, program manager of the Chemistry and Life Sciences Office, said that "risky," by ATP terms, means a technology risk, "Can it be done?" not a marketplace risk, "Will it be bought?" Also on the panel were Michael A. Schen, program manager of the Electronics and Photonics Technology Office, and Richard N. Spivack, an economist from the Economic Assessment Office.

Applications to ATP can come from individual for-profit companies or joint ventures, involving two or more for- profit companies, along with other partners and subcontractors. The panel gave examples of both large and small companies who have been funded by ATP. In the early 1990s, Nanophase Technologies was funded for synthesis and processing of nanocrystalline ceramics on a commercial scale. Recent projects have included Luna Innovations, Inc. to develop new medical applications of carbon nanomaterials, and projects on terabyte disk drives, organic integrated circuits, and microand nanoscale assembly led by companies such as General Electric, Motorola, and Zyvex Corporation. Various evaluation techniques are used to measure the success of these programs. For such high-risk ventures, the ATP program managers do not expect high weighting of success, but they do expect significant gains from the successes. New aspects of the program in 2001 included (a) rolling submissions and awards to help target the needed timeframe for best chances of project success, (b) a streamlined gated proposal process starting with a technical plan and business plan before semifinalists are chosen and awards made, and (c) pilot testing of a new electronic submission process. An independent assessment of the program by the National Research Council (NRC) suggested six reforms, although at the time of the seminar, Congress had not yet acted on these recommendations. NRC recommended that universities be allowed to lead joint ventures and to negotiate intellectual property. The Council also recommended new rules to encourage small and large companies to work together, and added strict guidelines to ensure funds are used to bridge "the valley of death." More information is available on the ATP Web site www. atp.nist.gov or by getting on the mailing list by calling or e-mailing 1-800-ATPfund or atp@nist.gov, respectively. 


\section{Panel Addresses Role of Materials Research in Counterterrorism}

On Monday evening, April 1, a special forum was held on Science and Counterterrorism to address how the materials research community can participate. Tomas Diaz de la Rubia of Lawrence Livermore National Laboratory (LNNL) introduced the forum and said he strongly believes scientists have a duty and a responsibility to lend their innovative talterrorism. The session, sponsored by LLNL, was chaired by Jay Davis, National Security Fellow at the Laboratory's Center for Global Security Research, and by Judy Kammeraad, Division Leader for Analytical and Nuclear Chemistry at LLNL. Panelists came from a spectrum of institutions including DARPA, U.S. Congress, Sandia National Laboratories, The Johns Hopkins University, and the U.S. Federal Bureau of Investigation (FBI). The presentations were followed by a brief panel discussion and a questionand-answer session.

Amy Alving, director of the Special Projects Office at DARPA, set the tone for the forum, giving a broad overview of challenges to be met from biological and chemical threats, particularly focusing on biosensors. There is a great need to develop sensors of appropriate response time, sensitivity, and selectivity to detect dangers and protect the population, with minimal false alarms, she said (see figure). Forensics used as a basis for retaliation may allow response times of days or weeks, while detection to protect against harm to civilians ents and scientific intuition to the war on

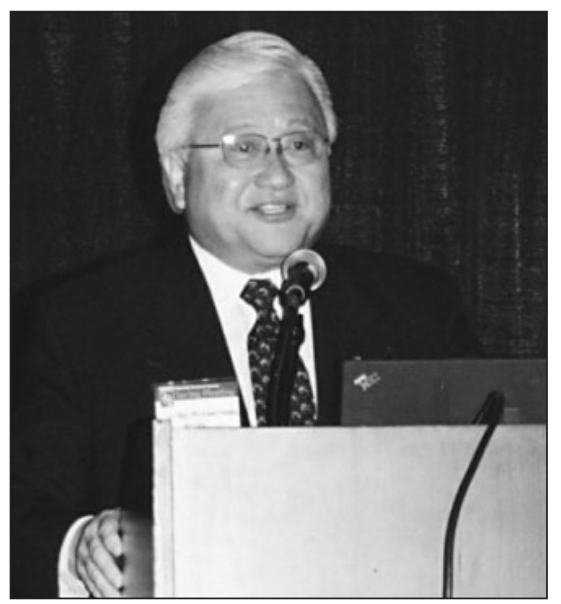

U.S. Rep. Michael Honda (D-Calif.) spoke at the panel discussion on materials research and counterterrorism, where he emphasized the necessary relationship between scientists and policy makers.

might require response times of less than a minute. Various approaches are being considered using antibodies, nucleic acids, time-of-flight mass spectrometry, or live cells. In addition to the need of sensors to detect what is there, delivery mechanisms are needed to communicate this information to a scale that a person can recognize, Alving said. Such "reporting technologies" could include fluorescent tags, mass loading to change the natural frequency of a lever arm, induced chemical reactions, light absorption emission, elec-

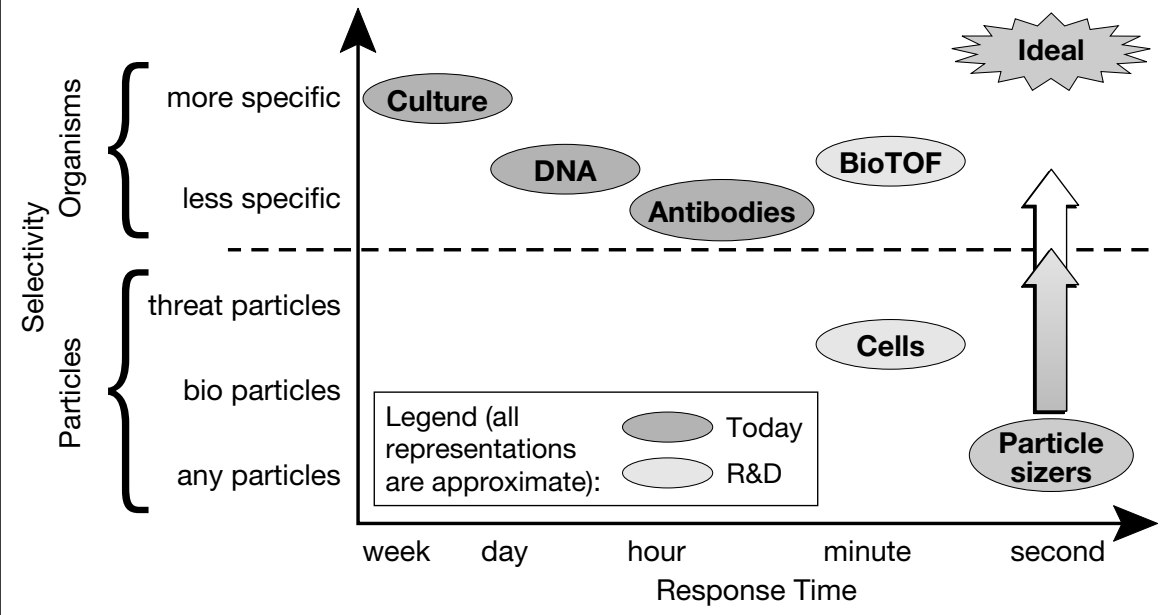

Figure. Trade-off of speed of detection and selectivity for various environmental sensors. BioTOF is a biological time-of-flight sensor. Compiled by the Special Projects Office of DARPA. tron or ion flow, or a magnetic field. In addition, the environment causes a lot of problems, Alving said, so sensors need to be characterized in the environment where they will be used. One example of an application that requires extremely fast biosensors is found in DARPA's building protection program. Here, the goals are to prevent harmful agents from reaching people by intercepting or by neutralizing the agents, then returning buildings to functionality quickly, while also preserving forensic evidence. Alving invited materials scientists to contribute to any of the numerous materials-related challenges in the development of sensors.

U.S. Rep. Michael Honda (D-Calif.), who has played a large role in establishing a nonpartisan climate for the discussion of Homeland Security, gave his impressions and lessons learned from watching this subject develop and mature in Washington. Honda spent his first few months in office learning as much as he could about the landscape of technology. After the September 11 attacks, he said he was forced to move from acquisition of information to dissemination and processing based on what he "already understood at that moment." He said that this is an opportunity for scientists to teach policy makers how to use science and technology to address homeland security issues.

"What you do on a daily basis means something, [and] it can be applied to enhance our security and our quality of life, " Honda said.

However, he said, in the present day society, scientists do not have the same high profile as athletes, for example. Materials scientists may enable technologies such as sports equipment, but "it is up to the scientists to make themselves more visible," he said. He urged scientists to invite their congresspersonand other local policy makers- to their laboratories to see their work.

Duane Lindner, deputy director of Chem/Bio programs at Sandia in Livermore, Calif., gave a presentation on recent developments in chemical and biological counterterrorism, building on some of the concepts presented by Alving. It is a challenge to detect a tiny amount of an agent in a background of a myriad of similar but perfectly innocuous and common agents. For instance, organo-phosphorus-containing pesticides are chemically very similar to nerve agents, Lindner said. Dealing with genetically engineered bio-threats creates a new Continued on page 557. 


\section{Continued from page 556.}

challenge. One option is to design synthetic antibodies by making use of the highly developed human immune system. Since "the speed of detection translates to lots of people living and dying," he said, detection methods are needed that are faster, more sensitive, and more selective than currently possible. Miniaturized and high-throughput analytical instruments can help, he said. Another innovative technology is the "gene chip." Using photolithography, thousands or tens of thousands of different polynucleic acid sequences can be built on a derivitized glass substrate, introducing a specific base sequence. The final result is a complex array structure that has unique and in some sense addressable nucleic acid sequence in every spot in the array. Gene chips can be used to do quick medical assays, Lindner said, or perhaps in the future to screen emergency room patients for all known pathogens.

Next, Kammeraad introduced the last two speakers, starting with Frederick "Skip" Burkle. He is Senior Scholar and Visiting Professor at the Center for International Emergency Disaster and Refugee Studies in the Schools of Medicine and Public Health, at The Johns Hopkins University. Burkle stated that the United States and the world "lack a critical public health system that can respond to a large-scale bioterrorist event," citing the failures of responding even to the small-scale anthrax attack. In addition, the United States lacks a modern health surveillance system to detect real-time infectious agents, he said. He gave another poignant example of how a detector during the Persian Gulf War falsely signaled Sarin was present on a hospitalized patient (counter to triage observation, and later found to be triggered by the anesthesia). If not for human intervention, this could have caused evacuation of the hospital and many needless casualties.

"We need to [be able to] trust the technology and we need to ensure that

are required for future technologies. Several presenters tested existing theories for dopant activation. Characterization of these doped materials requires high-resolution profiling at nanometer dimensions. Z-contrast TEM was used to investigate the position and possible cluster sites for antimony in silicon, which gave insight into the atomic-level positions of deactivated atoms. it is value-added to our clinical impression," he said.

Burkle suggested specific approaches to take to handle bioterrorism attacks from a healthcare provider's point of view. He cited the need for effectiveness measures, the value of mathematical modeling to help predict the spread of disease, and-keeping in mind the complexities of the decision-making process-the need for a reporting scheme with ways to manage the consequences and a set timeline for response.

Randy Murch (Deputy Director, FBI Laboratory) discussed forensic and legal aspects of counterterrorism. Forensics is extremely important in terrorist events to determine the extent of response and retribution toward adversaries. Forensic evidence used in such cases "had better be right, better be valid, and better be credible," he said. He emphasized the importance of obtaining independent corroboration and watching for alternative explanations. Forensics can help paint a picture and fill in gaps beyond the normal investigation, providing starting points, leads, and sometimes proof. However, he cautioned that "there is no one single silver bullet in forensic science." Rather a matrix needs to be applied. Forensics now exists on a number of different levels: macro (crime scene), micro (microchemistry, microscopy, DNA analysis), nano/molecular, and informatics. A "gray-scale" is used, spanning from exclusion to absolute attribution. Fingerprints, DNA, or a fracture can be used for absolute attribution.

"Do you know that you cannot tear a roll of tape the same way twice?" Murch said. "That's absolute attribution," not unlike DNA evidence. "So, we constantly seek techniques, methodologies, instruments, sensors, if you will, that push us farther and farther to the right toward attribution, or more quickly allow us to exclude."

The presenters gave a plea to materials scientists to use the tools at their disposal to address the challenges that remain to combat terrorist threats.

Symposium Support: Fujitsu, Intel, Verdant Technologies, Applied Materials, and Varian Semiconductor Equipment.

\section{Theory and Experiment Help Unravel Complexities of Perovskites}

(See MRS Proceedings Volume 718)

Perovskites form a large class of materials and are deceptively simple in basic structure but immensely complex in com- positional variations, symmetry changes, and physical properties. They include ferroelectrics, magnetoresistive materials, oxide ion and proton conductors, superconductors, and an abundant phase in the Earth's lower mantle. A recurring theme in Symposium D was the interplay of theory and experiment in understanding and predicting properties of perovskites. Among two sessions devoted to theory and modeling, one emphasized phase changes and elasticity of Earth materials such as $\mathrm{MgSiO}_{3}$ and $\mathrm{CaSiO}_{3}$, and the other emphasized new magnetic and ferroelectric materials, including thin films and multilayers. These were complemented by experimental studies of the synthesis of new families of perovskites and property measurements. Systematic crystal chemical controls on structure and stability were presented by J.P. Attfield (Cambridge), P. Battle (Oxford), P. Woodward (Ohio State), and others. The role of coupled vacancy substitution was explored for a new class of niobate perovskites $(\mathrm{H}$. Xu, UC-Davis), for silicate perovskites containing aluminum (A. Navrotsky, UC-Davis; C.A. McCammon, Univ. of Bayreuth), layered manganites (J.F. Mitchell, ANL), and other materials. The importance of cation ordering in determining physical properties was emphasized in several presentations (P. Davies, Univ. of Pennsylvania; A. Rappe, Univ. of Pennsylvania). There was extensive discussion, with about 20 oral and poster papers about lead zirconate titanate, niobate and tantalate ferroelectrics, and manganites. K.M. Rabe (Rutgers) presented first-principles calculations of the properties of perovskite thin films and multilayers. These were complemented by about five experimental studies. There are significant advances in synthesis techniques, including high pressure (M. Azuma, Kyoto Univ.; K. Yamaura, Natl. Inst. for Materials Science, Tsukuba), for perovskites with ions of variable valence.

\section{Magnetic Media for Data Storage Turns to Nanostructures} (See MRS Proceedings Volume 721)

Symposium E covered a wide span of synthesis, characterization, and measurements of nanostructural magnetic materials for data storage. The symposium devoted its first three sessions to physical, chemical, and biological nanostructural patterning magnetic materials. C. Rettner (IBM Almaden Research Center) presented the current IBM efforts on patterned media and showed recording densities in excess of $140 \mathrm{Gbit} / \mathrm{in}^{2}$. R. Cowburn (Durham Univ., UK) presented three related talks on FIB patterned permalloy structures where 
magnetostatic coupling for different configurations of patterns, including magnetic rings, was investigated. Also presented was novel work on logic operations using patterned magnetic arrays, where the stability of a NOT operation was demonstrated for 50,000 cycles. K.M. Krishnan (Univ. of Washington) and T. Hyeon (Seoul Natl. Univ., Korea) reported their chemical routes to achieve self-assembled magnetic nanocrystallites where the use of different surfactants gave control over particle size and shape. A. Belcher (Univ. of Texas, Austin) described some of the new and exciting ideas to use biological methods (viruses and bacterium) to create magnetic and other nanostructured materials.

D. Awschalom (UCSB) presented work on spin manipulation in hybrid ferromagnetic/semiconductor systems probed using the Faraday rotation. The effect of nuclear spins on the electronic spin system was discussed in terms of imprinting the magnetization from a ferromagnet into the nuclear spins of a semiconductor.

In a joint session with Symposium J, M. Doerner (IBM, Storage Technology Division) addressed the microstructural effects on single layer and antiferromagnetically coupled longitudinal magnetic recording media. In the session dedicated to materials for magnetic recording heads, H. Ohldag (Stanford) emphasized the importance of oxidation layers on the antiferromagnetic/ferromagnetic coupling widely exploited in magnetic recording read sensors and advanced media. S. Wang (Stanford) introduced the possible application of $\mathrm{CoFeAl}$ as a candidate writer material for recording heads and inductors. H. Okumura (CMU) reviewed his group's work on nanocrystalline soft magnetic materials for data storage. $\mathrm{Zr}$ and Hf-containing HITPERM-a material that has soft magnetic properties that persist to high temperatures, in this case, $\left((\mathrm{Fe}, \mathrm{Co})_{88}(\mathrm{Zr}, \mathrm{Hf})_{7} \mathrm{~B}_{4} \mathrm{Cu}\right)$ - achieved saturation induction of $1.7 \mathrm{~T}$ and $2.1 \mathrm{~T}$, respectively. The magnetic recording media session focused on materials for perpendicular magnetic recording. M. Futamoto (Hitachi) reported detailed microstructural analysis highlighting the need to minimize stackingfault generation in the fabrication of perpendicular media. D. Weller (Seagate) discussed the feasibility of recording at $1 \mathrm{Tbit} /$ in. $^{2}$ as a difficult but achievable goal using the perpendicular configuration. Two talks by G. Hussen and B.M. Clemens (Stanford) on the possible application of spinodal decomposition in thin films as recording media attracted a lot of interest and discussions.

Symposium Support: Intevac, Heraeus MTD, Seagate, Western Digital, Veeco Instruments, and IBM Almaden Research Center.

\section{Graduate Students Receive Gold and Silver Awards}

During the awards ceremony held on April 3 at the 2002 Materials Research Society Spring Meeting, 27 graduate student finalists received Gold and Silver Awards. See MRS Bulletin, April 2002, page 336 for the title of their papers.

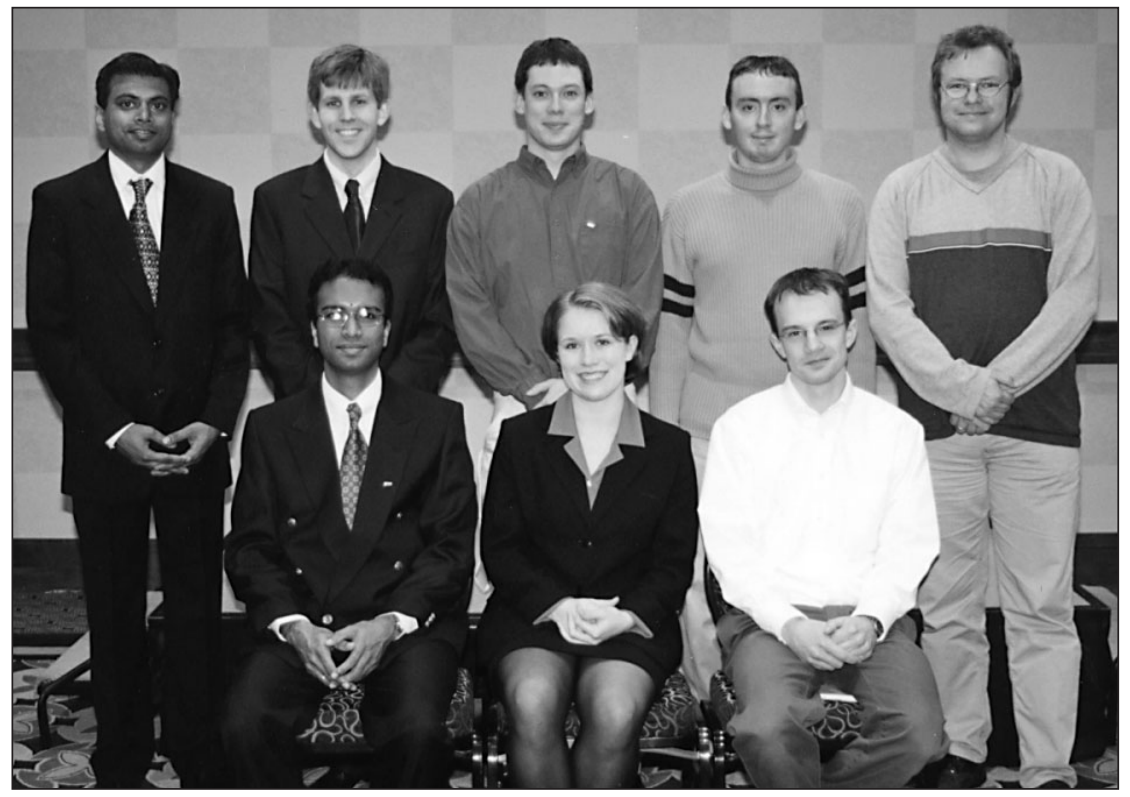

Gold Graduate Student Awards went to (front row, left to right): Saravanapriyan Sriraman (UCSB), Christy L. Haynes (Northwestern), and Michael E. Groenert (MIT); (back row, left to right): Sumit Agarwal (UCSB), Erik D. Spoerke (Northwestern), Job Rijssenbeek (Northwestern), Michael Lufaso (Ohio State), and Hendrik Ohldag (Stanford). Not shown: Matthew Robinson (UCSB)

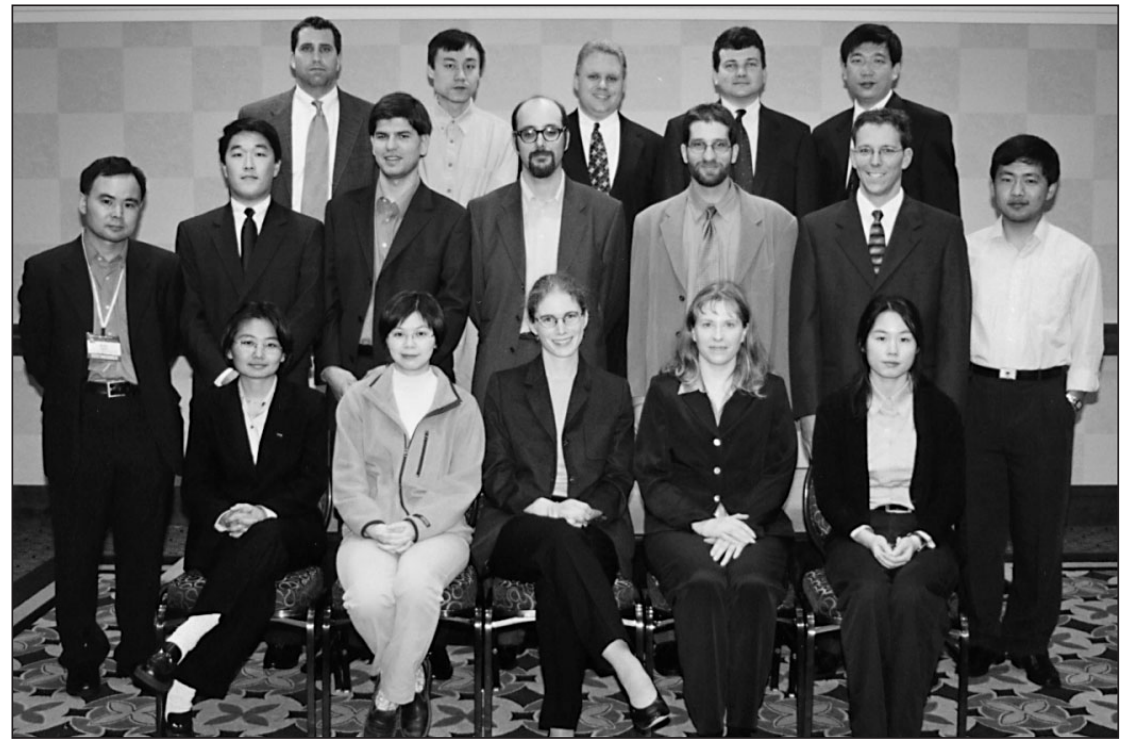

Silver Graduate Student Awards went to (front row, left to right): Yayoi Takamura (Stanford), Yu Huang (Harvard), Lara A. Estroff (Yale), Amanda J. Haes (Northwestern), and So-Jung Park (Northwestern); (center row, left to right): Hong Meng (UCLA), Jason Lee (Univ. of Illinois, Urbana-Champaign), Melik C. Demirel (LANL), Stefano Curtarolo (MIT), Eli D. Sone (Northwestern), Rhett Brewer (Caltech), and Haoquan Yan (UC-Berkeley); (back row, left to right): Mark E. Byrne (Purdue), Xiaogang Liu (Northwestern), Eric W. Seelig (Northwestern), Vadam Adamovich (Univ. of Southern California), and Guofeng Wang (Caltech). Not shown: Leila Rezaee (Univ. of Tehran, Iran). 


\section{Defect Engineering Finds Its Way into Devices}

(See MRS Proceedings Volume 719)

In Symposium F on Defect- and Impurity-Engineered Semiconductors and Devices, the growing maturity of the topic was reflected by the vast majority of presentations that dealt with the engineering aspects of defects, rather than simply dealing with defect control and characterization. The role of hydrogen in semiconductor defect passivation and impurity interaction with many potential uses was addressed by a number of researchers. C. Van de Walle (PARC, Palo Alto) outlined his theoretical results on defect and impurity engineering and the role of hydrogen on the conductivity of $\mathrm{ZnO}$, a wide-gap semiconductor with diverse applications. M. Capizzi (Univ. of Rome) presented results on the efficient passivation effect of nitrogen atoms in GaAsN alloys. E.V.K. Rao (CNRS/LPN, Bagneux) spoke about the use of hydrogen plasma treatment to significantly reduce the propagation losses in $\mathrm{InP}$ photonic circuits operating at $1.56 \mu \mathrm{m}$.

Hydrogen in diamond is also of major interest, with a profound impact on the bulk and surface properties of the material. In particular, N-H-N complexes are theoretically predicted to be relatively shallow donors in diamond. The hydrogeninduced surface conductivity of diamond has reached a good level of understanding by revealing the essential role of adsorbates. FETs using the hydrogen surface conductive channel have been realized and even low temperature operation has been demonstrated. More surprisingly, the hole mobility in the hydrogenated surface layer of black diamond and the corresponding device performance are comparable to those of white and even single-crystal hydrogenated diamond.

Gettering of impurities with defect and void layers was another major topic of the symposium. Void and bubble formation mechanisms in semiconductors crystals based on helium implantation and the integrability of voids with standard semiconductor processing were demonstrated in a comprehensive review by V. Raineri (CNR-IMM, Catania) Applications of voids were also considered for polycrystalline layers with high thermal stability, lifetime engineering, improved reliability of devices, and nanosensors for interstitials. The need for a "vacancy implanter" in the toolbox of defect engineering and the use of vacancy-rich regions for dopant activation and strain engineering were addressed in an invited talk by A. Haynes (ORNL).

N. Kageshima (NTT, Atsugi) described the current interest in nitrogen doping of silicon that suppresses the aggregation of both vacancies and $\mathrm{Si}$ interstitials during the Si bulk crystal growth. According to the theoretical work of Kageshima's group, very stable $\mathrm{N}_{2} \mathrm{~V}_{2}$ complex formation is estimated to play an important role in the process.

Before the technical sessions started, the symposium held a full-day tutorial on Semiconductor Defect Chracterization by Deep-Level Transient Spectroscopy, pre- sented by Y.N. Mohapatra (IIT, Kanpur).

Symposium Support: Biemtron, Eastman Kodak, JOBIN-YVON, MEMC Electronic Materials, Mitsubishi Silicon America, NREL, Photowatt, $R$ Dec Company, SAIREM, Seki Technotron, SOITEC SA, SULA Technologies, THALES, and Unisoku.

\section{Electronic Displays and Devices Seek Flexible Substrates}

The inaugural symposium for MRS on materials for flexible electronic displays and devices was a bit of an experiment.

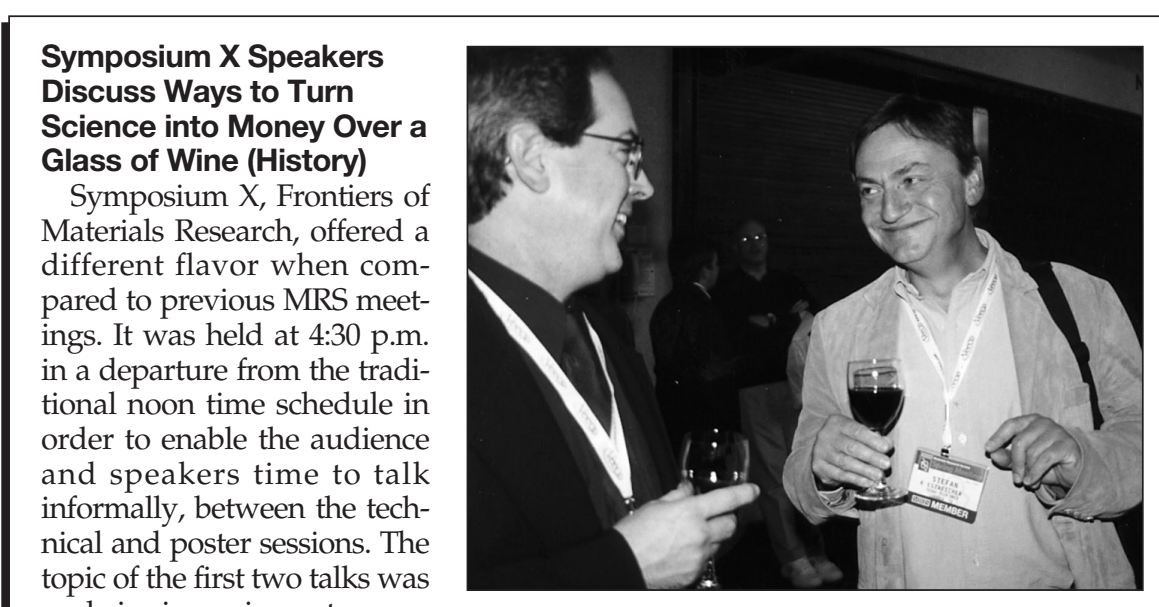

on bringing science to market. Bill Frezza of Adams Capital Management (Boston, Mass.) gave attendees some insights into the world of venture capital. He said that the typical materials researcher is good at turning "money into science" by obtaining grants, but the idea of venture capital is to turn "science into money." Frezza described the workings of venture capital investors and how they differ from corporate investors. He also gave suggestions and tips for starting up a company and obtaining venture capital. He said that the materials research community is well placed for starting up new companies based on the breadth and type of research work that is conducted.

Parviz Tayebati, in his talk, started with a brief background on his company "Coretek," which he founded for making MEMS devices relevant to the telecommunications industry and later sold to Nortel Networks. In his overview on the various issues to consider for setting up a company based on materials research, Tayebati said that the key goal is to create value. Among his suggestions are to start by identifying the market rather than the technology; de-risk the plan; understand market positioning and key players; engage customers at an early stage and have more than one customer; continue customer engagement at a more advanced stage; take appropriate steps for funding the company, which includes selecting the right venture capitalist, looking for angel investors, and commissioning an advisor/corporate lawyer; look for alternative funding such as government grants if the product is not mature; and learn the financial aspects of business.

Straying from the topic of venture capitalism, the third Symposium $X$ speaker, Stefan Estreicher (Texas Tech Univ.), explored materials in the history of wine. He opened his presentation with a quote by Edward VII (1841-1910), "One not only drinks wine, one smells it, observes it, tastes it, sips it and one talks about it." He gave a brief historical perspective in 45 minutes, describing materials used for maceration and fermentation, and materials used for the transportation of wine in the past 7500 years. Estreicher ended his talk with a quote by Aristophanes (448-385 B.C.), "Quickly bring me a beaker of wine, so that I may wet my mind and say something clever." In the reception that followed, wine was served. 
Rather than focus deeply on a single set of technologies, presentations in Symposium $G$ considered a broad range of technical approaches to solve a common issue: how best to develop electronic devices on flexible substrates. Flexible substrates place a number of severe demands on both the construction process as well as materials. For the most part, flexible substrates are not dimensionally rigid, cannot withstand high temperatures or corrosive environments, are sometimes contaminated or leaky, and can have coloration, polarization, or turbidity problems. Nevertheless, researchers provided a number of clever approaches to developing different types of electronic devices on flex.

The first day of sessions focused on inorganic electronics, including talks on lowtemperature polysilicon display backplanes by D.P. Gosain (Sony), a novel lift-off and transfer process of $p$-Si by S. Inoue (Seiko Epson), and a fluidic self-assembly approach of CMOS circuits by R.G. Stewart (Alien). A joint session with Symposium P,

\section{Dielectrics Form Basis of Tunable and Microwave Devices \\ (See MRS Proceedings Volume 720)}

Advances in the field of tunable dielectrics for next-generation frequency agile microwave electronics were reported in Symposium H. At issue is a material that exhibits a large dc-induced change in the dielectric constant, with an extremely low dielectric loss. Conventional approaches have used ferroelectric materials, highly polarizable dielectrics such as $(\mathrm{Ba}, \mathrm{Sr}) \mathrm{TiO}_{3}(\mathrm{BST})$ in the paraelectric phase (no remnant polarization) as a material that is tunable, but with moderate dielectric loss. Researchers in the field have been divided on an approach to improve the materials' properties. These include efforts pioneered by the U.S. Army Research Laboratories (ARL) that involved mixed-phase materials, to the current search by The Pennsylvania State University for new materials. In addition, characterization of the high-frequency properties of these materials presents its own challenges. NIST researchers have developed procedures and models to characterize the dielectric response of films from $\mathrm{kHz}$ to $\mathrm{GHz}$ frequencies while NASA has used the modeling of BST-based phase shifters, designed for their reflect-array antenna, as a tool to measure intrinsic materials properties. Stuart Wolf (DARPA) presented a summary briefing on his agency's three-year effort entitled "frequency agile materials for electronics" (FAME). Among the successes reported in this program are devices such as electronically steerable antennas, tunable phase shifters, and tunable filters at microwave frequencies that can now be used for a wide range of military applications. UCSB reported the fabrication of a distributed phase shifter based on BST thin films that showed $90^{\circ}$ of phase shift at Ku-band for each $\mathrm{dB}$ of insertion loss, better than current MEMS- or GaAs-based technologies (see Figure). While the initially designed Army materials serve as the basis for a family of tunable microwave products currently manufactured by Paratek Microwave, ARL continues to develop new, single-phase materials based on multivalent site substitutions in the BST family, with properties tailored specifically to advanced radar antennas. Also, the Pb-based analogue of $\mathrm{BST},(\mathrm{Pb}, \mathrm{Sr}) \mathrm{TiO}_{3}$, is being actively investigated by PSU, Arizona State, and the University of Puerto Rico as a candidate replacement material for BST. The presentations at the Symposium showed that a variety of approaches to material processing were yielding materials and devices with comparable or higher figures of merit, compared to semiconducting- and ferrite-based technologies, with an additional savings in device size, weight, and power consumption.

Symposium Support: ONR/DARPA and ARL.

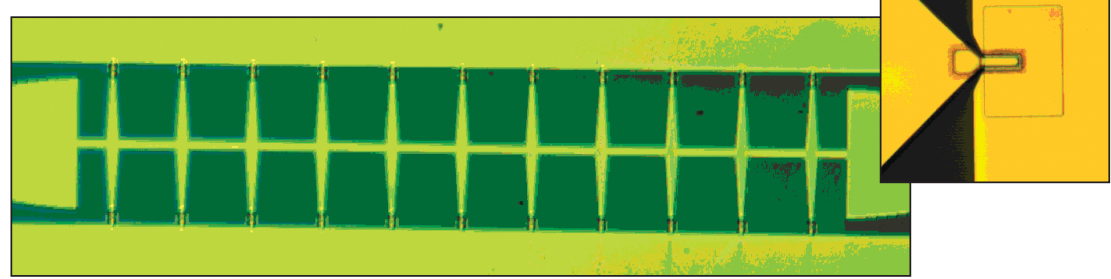

Figure 1. Distributed phase shifters based on BST thin films showing $90^{\circ}$ of phase shift at Ku-band for each dB of insertion loss. Inset: Enlarged view of the tunable capacitor in the delay line. Courtesy of R.A. York, University of Calif., Santa Barbara, College of Engineering, Dept. of Mat. Sci, Santa Barbara, CA 93106 USA.

on the second day, considered organic electronics, and included talks by A. Heeger (UCSB), Y. Yang (UCLA), P.E. Burrows (PNNL), H. Sirringhaus (Cambridge), and H.E. Katz (Lucent). The last day covered displays and power, with lectures by J.G. Innocenzo (DuPont) on roll-to-roll manufacturing, G.P. Bryan-Brown (ZBD Displays) and H. Kuma (Idemitsu Kosan) on plastic displays, and Y. Iwasa (Tohoku Univ.) on polymer batteries.

Symposium Support: Eastman Kodak and DARPA \&Army Research.

\section{Copper and Shallow Trenches Shaped by Chemical-Mechanical Polishing}

In Symposium I, major focus areas included the current new thrusts in CMP technology development, copper, and shallow trench isolation (STI) polishing. D.R. Evans (Sharp) started the sessions with an invited paper on the technical issues of copper CMP. This was followed, during the rest of the symposium, by several presentations on different aspects of copper CMP such as abrasive-free polishing of copper and the minimization of post-CMP topography.

D. Stein (SNL) and K. Devriendt (IMEC) provided a summary of the integration issues surrounding STI CMP. Several presentations also focused on pad technology, a growing area of interest in CMP.

The progress of CMP technology was reflected in the invited talk by $\mathrm{D}$. Boning (MIT) on nanotopography of silicon wafers and its impact on CMP. Small variations in the planarity of the underlying topography of the silicon wafer can lead to thickness variations in the final polished oxide layer in STI polishing.

A further very positive development was the increase in the number and scope of presentations addressing basic CMP mechanisms, both from an experimental viewpoint as well as more theoretical approaches. CMP applications in semiconductor technology, in general, outpace the understanding of the underlying mechanisms. The CMP mechanism-oriented papers covered a wide range of issues from details of abrasive-free copper polishing to fluid dynamics between the CMP pad and wafer.

\section{Links between Texture, Microstructure, and Properties Examined in Electronic and Magnetic Films}

(See MRS Proceedings Volume 721)

Symposium J, Texture and Microstructure in Electronic and Magnetic Films, reflected the growing interest in textural and microstructural control in thin-film technology. The materials systems in which links between texture, microstruc- 


\section{Poster Prizes Awarded at the 2002 MRS Spring Meeting}

The 2002 MRS Spring Meeting Chairs Zhenan Bao (Bell Laboratories/Lucent Technologies), Eugene A. Fitzgerald (Massachusetts Institute of Technology), Ulrich M. Gösele (Max Planck Institute for Microstructure Physics, Halle), and Kenneth P. Rodbell (IBM T.J. Watson Research Center) awarded prizes for the best poster presentations. Awards were given based on the posters' technical content, appearance, and graphic excellence. Posters presented by students who received grants under the MRS Undergraduate Materials Research Initiative (UMRI) were judged separately by the Academic Affairs Committee Chair Linda Vanasupa (California Polytech State University) and the UMRI subcommittee chair Ingrid St. Omer (Northern Arizona University).

Awarded posters and their authors were (A8.5) 1-D Ordering of Self-Assembled Ge Dots on Photolithographically Patterned Si (001) Stripes, B. Yang, A.R. Woll, P. Rugheimer, and M.G. Lagally (Univ. of Wisconsin, Madison); (L5.2) Large-Area Porous Alumina Photonic Crystals via Imprint Method, J. Choi, J. Schilling, K. Nielsch, R. Hillebrand, M. Reiche, R.B. Wehrspohn, and U. Gösele (MPI of Microstructure Physics, Halle); (N7.4) Display of Estrogen Receptor on Biomagnetite and Detection of Estrogen-Like Chemicals, T. Yoshino, T. Masayoshi, Y. Okamura, T. Haruko, and T. Matsunaga (Tokyo Univ. of Agriculture and Technology); (N8.5) Guidance Channel Development: Controlled Release of NGF from PLGA Scaffolds, S.E. Stabenfeldt and R. Kuntz Willits (Saint Louis Univ.); (Q6.32) Multilength-Scale Ordering of ZnS Nanocrystals using Genetically Engineered Bacteriophage Liquid Crystal Systems, S.-W. Lee, C. Mao, C.E. Flynn,

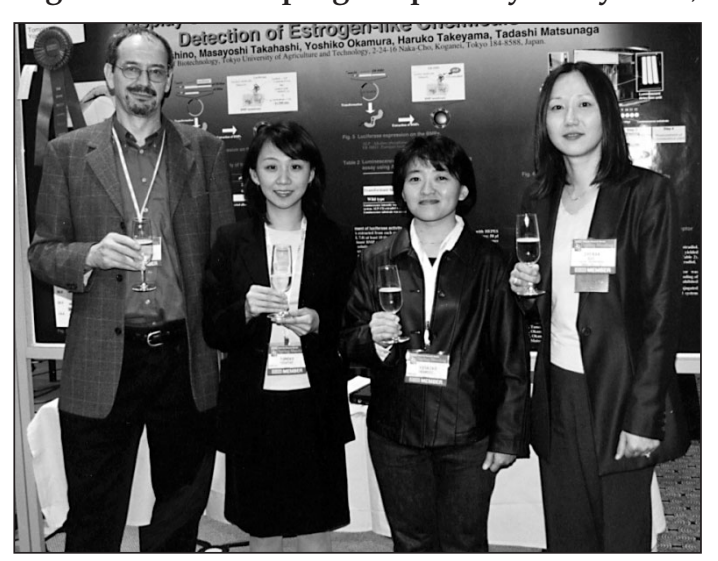
and A.M. Belcher (Univ. of Texas, Austin); (R10.8) SnGe Quantum Wire and Sn Quantum Dot Formation via Phase Separation, R. Ragan and H.A. Atwater (Caltech); and (W8.3) Modeling and Numerical Simulations of Microdiffraction from Deformed Crystals, R. Barabash, and G. Ice (ORNL). Awarded UMRI posters and authors were (UMRI-8) Tribological Testing of Novel Carbide-Derived Carbon Coatings for Biomedical Applications, B. Carroll (Drexel), advisor: Y. Gogotsi; (UMRI27) Hybrid Polymer Materials Development for Microfluidic Applications, J. Polefrone (James Madison Univ.), advisor: B.H. Augustine; (UMRI-28) Fabrication and Characterization of Core-Shell Nanoparticle Assemblies, B. Sadtler (Purdue), advisor: A. Wei; and (UMRI-37) Modeling Compressive Plastic Deformation in an Aluminum Cylinder using MESPI, J. Trethewey (Penn State), advisor: B. Tittmann.

ture, and properties were studied included metal films, with particular emphasis on copper; electronic films, including ferroelectrics and transparent conducting oxides; and magnetic films, in a joint session with Symposium E. The presentations displayed a significant variation in the sophistication of the texture measurements techniques, depending on the application for which the data were required, and, in some cases, the equipment available to the researchers. The technique of electron backscatter diffraction, which yields information on texture, microstructure, and microtexture, was strongly featured.

In the session on techniques, K. Kozaczek (Hypernex, Inc.) described recent advancements in $x$-ray instrumentation that combined texture and phase analysis capabilities with high spatial resolution. He presented the application of this tool to damascene copper metallization. Copper metallization was the subject of more than a quarter of the talks. The consensus that emerged was that the evolution of copper texture in fine lines was more complexdue to transients and twinning - than in the corresponding $\mathrm{Al}$ system, but there was no definitive evidence linking texture to electromigration failure. Further study was needed in this area as well as in stress voiding and yield.

The use of texture to optimize the performance of electronic materials was illustrated by G. Fox (Ramtron) who described how highly textured $\mathrm{PbZr}_{0.4} \mathrm{Ti}_{0.6} \mathrm{O}_{3}$ thin films are used in ferroelectric nonvolatile memory, with significant property advan- tages. The texture was controllable and the effects of texture on properties were successfully modeled. C. Thompson (MIT) reviewed the development and evolution of texture in polycrystalline thin films, and two talks addressed simulation studies on film growth during copper and tantalum deposition.

Symposium Support: Bruker AXS, HyperNex, HKL Technology, and EDAX.

From Solid-State Lighting to Quantum Dots, Optoelectronics Shows Promise, but Substantial Challenges

(See MRS Proceedings Volume 722)

The talks presented in Symposium K delivered the anticipated message that substantial materials science challenges face this broadly based optotechnology that 


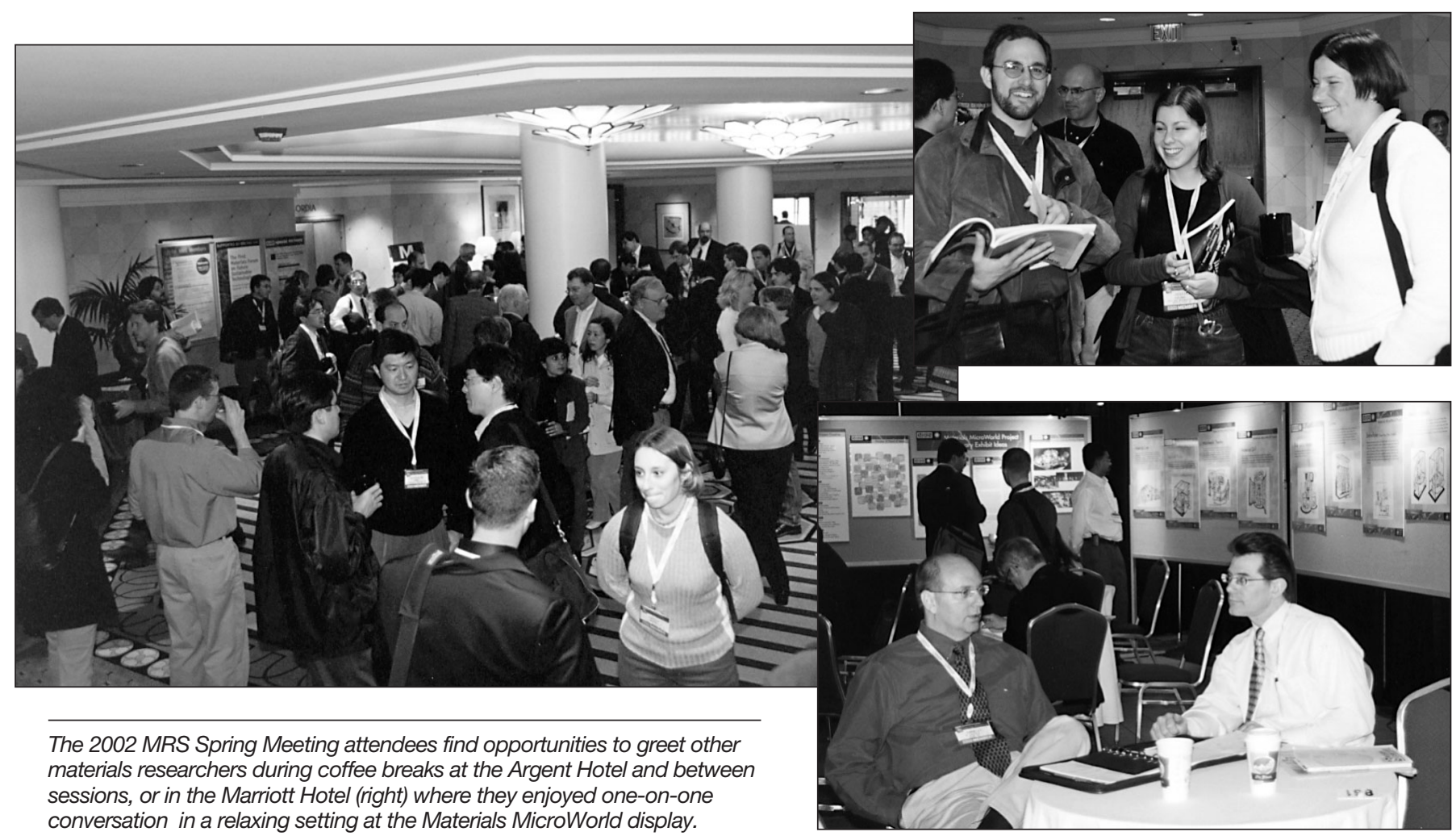

covers a wavelength span from $200 \mathrm{~nm}$ to $5 \mu \mathrm{m}$. Even though substantial progress has been made in materials for solid-state lighting in the form of nitride emitters, organics (by virtue of multilayer synthesis), and device geometry (high emission design), these accomplishments lack enough output power to replace conventional incandescent lighting. Perhaps largearea single-crystal AlN substrates, that were reported to have reached sizes of the order of 1 in. ${ }^{2}$, might further enable nonpolar epitaxy to improve the internal quantum efficiencies reported for nitride-based emitters. Integration technologies illustrated the reality of marrying $\mathrm{III}-\mathrm{V}$ optics to $\mathrm{Si}$ electronics by examples containing 5000 GaAs-based diodes on CMOS with device yields of 0.9999 at the die level. Longer range milestones of achieving full waferscale integration prospects were reported by examples of a GaAs laser on Si by direct epitaxy. Longer lived edge-emitting lasers were achieved by introducing chemicalmechanical polishing and strain-relieved epitaxy to impact this long-standing technology challenge. There were notable results in long-wave VCSELs technology that were illustrated by the materials system of InGaAsNb. With molecular-beam epitaxy, lasers with wavelengths out to $1.5 \mu \mathrm{m}$ were achieved on GaAs substrates.
In addition, quantum dots of InGaAs were reported to have internal slope efficiencies of nearly one at $1.3 \mu \mathrm{m}$. The tutorial instructor, S.K. Tewksbury (Stevens Inst. of Technology), presented a high-level view of how materials and devices are important to the telecommunication industry and how advances in materials in devices are essential to enable future systems.

\section{Theory and Characterization Elucidate Losses in Photonic Components} (See MRS Proceedings Volume 722)

A tutorial for Symposium L, Photonic Crystals-From Materials to Devices, provided an overview of the current state of the art in photonic-crystal research. In the technical sessions, presentations from theory over material issues to optical characterization of photonic-crystal components were given. From theoretical analysis as well as optical characterization, it was shown that the commonly used 2D slab structures exhibit losses and reflections when bends or splitters are integrated. It seems as though 3D photonic crystals will become more important in the forthcoming years since they might resolve some of these problems. Novel approaches and recent improvements of 3D photonic crystals were presented theoretically and experimentally in the Symposium. Moreover, recent results on photonic-crystal fibers and their areas of application were discussed.

\section{Surface Characteristics Important for Biomaterials}

(See MRS Proceedings Volume 724)

Characterization and imaging techniques of biomaterials was the theme of Symposium $\mathrm{N}$ on biological and biomimetic materials. Living organism interactions with organic and/or inorganic materials comprised the bulk of the presentations. Egg, nut and sea-shells, silk (natural and artificial), peptide and protein architectures, and cellular materials were represented along with traditional materials such as ceramics, polymers, and metals.

Many researchers discussed surface patterning to promote the attachment and growth of specific molecules. The role of surface morphology (roughness) on cell adhesion was also considered. A research group at Cornell University reported that patterned silicon columns could be made to increase and direct the dendritic growth of nerve cells. In an implant-related study, it was reported by a group at the University of Washington that calcification of implants could be inhibited by the presence of a naturally occurring molecule, osteoportin. This has 
tremendous impact on the biocompatibility of contact lenses, artificial bladders, and cardiac valves, for example.

Symposium Support: ARO; LLNL; and Lucent Technologies, Bell Labs.

\section{Specificity and Signal Transduction Needed for Chemical and Biological Sensors to Detect and Protect \\ (See MRS Proceedings Volume 723)}

Symposium $\mathrm{O}$ focused on chemical and biological sensors and the techniques needed to integrate them into practical devices. Researchers addressed the current technologies, their shortfalls, and the challenges that lay ahead.

An efficient approach to collect, concentrate, and process air- and water-borne samples has not yet emerged, and it comprises a significant challenge. A variety of microfluidics and MEMs devices that can be used for sample collection, concentration, and preparation were discussed. Presentations from researchers at ACLARA Biosciences showed the progress that has been made in the development of injection-molded plastic microfluidic devices and their application to bioassays. The use of polymer-laminate systems to allow rapid prototyping and testing of microfluidic devices was demonstrated by P. Yager (Univ. of Washington). Additionally, some elegant applications of soft lithography and microcontact printing to this problem were presented by R. Nuzzo (Univ. of Illinois). Several of the presentations also focused on materials, such as hydrogels and dendrimers, that can be key components in sample handling devices.

In the area of chemical and biological detectors, participants discussed detection of conventional toxins; toxic industrial compounds; chemical warfare agents such as blood, nerve, and blister agents; and explosives. Biological sensors discussed in the presentations targeted proteins, carbohydrates, and oligonucleotides. In general, the detection problem can be viewed in two parts: chemical identification and signal transduction. The chemical identification part of the problem involves some specific or nonspecific chemical recognition element that displays a unique response to the analyte of interest. Three general schemes for providing chemical specificity or identification were discussed: methods based on electronic energy levels (by fluorescence quenching, electrical conductivity, or redox properties of analytes), cross reactive (nonspecific) arrays, and specific molecular recognition as is found in the traditional antibody-based assay.

A cross-reactive array, or "electronic nose," behaves like the mammalian olfac- tion system; the response from an array of a few to thousands of individual sensor elements is combined to form a response pattern that is characteristic of the analyte of interest. Various implementations of this basic concept were discussed. D. Walt (Tufts) provided an example of how multiple redundant sensor elements can be used to improve the signal-to-noise ratio of the experiment. Although the usual implementation of an "electronic nose" targets analytes in the gas phase, it was pointed out that this technique is also applicable to detection of species in water.

Nature provides many examples of how specific binding of two complementary molecules can be used to achieve molecular recognition. Examples include an antigen-antibody pair or the DNA duplex. Indeed, many of the presenters showed transduction schemes that incorporated biological molecules. This approach has the advantage that the sensor designer can rely on 2 billion years of evolution to choose the recognition elements, and it works particularly well for detection of bio- logically derived molecules. In the case where there are no naturally occurring molecules to do the recognition, researchers must rely on chemical- or biosynthesis. Examples came from S. Daunert (Univ. of Kentucky), who presented a variety of approaches to sensing biological agents based on the products of genetic engineering; from $\mathrm{H}$. Bayley (Texas A\&M), who discussed pore-forming proteins that have been constructed to measure very low levels of analyte; and from T. Swager (MIT), who described amplified luminescent polymers that can specifically sense explosives. Other examples of molecules that had been designed for specific recognition were provided in many of the presentations.

For any of the recognition schemes just described, a quantifiable signal must ultimately be generated. This process is referred to as signal transduction. Participants in the Symposium described a variety of optical, electrical, and mechanical methods of signal transduction. For example, the measurement of fluorescence from a rare-earth element, ampli-

Molecularly Imprinted Materials Find Uses as Biosensors and in Nanotechnology (See MRS Proceedings Volume 723)

Symposium M was the first symposium on molecularly imprinted (MI) materials held by MRS. The basic science of the field has matured with regard to synthesis and characterization, yet much work remains to be done. The field has also matured in the areas of application including sensors, catalysis, and separations science. The announcements by Aspira Biosystems and other companies of new commercial products is a clear indicator that MI materials are now fulfilling the promise.

F. Dickert (Vienna Univ.) presented his group's recent success imprinting polyurethane with yeast cells and the tobacco mosaic virus (TMV). AFM images provided evidence for the high quality of the imprinting. One particularly striking image revealed an imprint formed by a yeast cell caught in the act of dividing (see Figure). Using this new imprinted polyurethane, the Dickert group has made a sensor that can detect TMV at concentrations as low as 0.005 $\mu \mathrm{g} / \mathrm{mL}$. The Dickert group's work could lead to improved biosensors.

N. Perez (Univ. of East Anglia) and M. Whitcombe (UK Inst. of Food Research) have developed steroid imprinted core-shell nanoparticles. Their work holds great promise for the advancement of nanotechnology based on MI materials.

K. Shimizu (Univ. of South Carolina) advocates the LangmuirFreundlich binding models for MI materials. He has shown that this type of analysis leads to more meaningful conclusions about the quality of imprinting than the more commonly used one-site binding models.

Symposium Support: GlaxoSmithKline, Dow Corning, and Petroleum Research Fund.

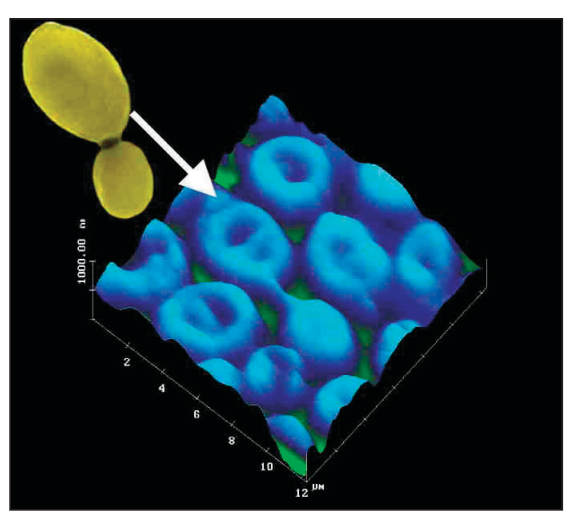

Figure. Imprinting of polyurethane by using yeast cells. The arrow points to an imprint that caught a yeast cell dividing. This imprinting technology can be used as a biosensor, for instance, to detect the tobacco mosaic virus. 
fied by sensitizers naturally present in bacterial endospores such as anthrax, was described by N. Fell (ARL). An example of an electrical measurement that can be used as a transducer is the conductivity of nanowires. Transduction based on nanowire conductivity has recently emerged as a technique that can be very sensitive, and R. Penner (UCIrvine) presented one example of this approach: the use of palladium nanowires to detect hydrogen gas at low levels under industrially relevant conditions. An example of a mechanical measurement that can be used for signal transduction is the monitoring of microscopic deflection of microcantilevers. This approach was discussed by G. Muralidharan (ORNL), for example. In addition, a variety of methods based on optical reflection, diffraction, absorption, or plasmon resonance were presented.

Symposium Support: ONR and ACLARA Biosciences.

\section{Polymers and Small Molecules Show Their Glow in LEDs and Electronic Applications} (See MRS Proceedings Volume 725 )

In Symposium P, developments in the field of organic (molecular and polymeric) electronic and optoelectronic materials and devices were presented. Some of the highlights were the findings of fluorescent polymers, developed by A. Jen (Univ. of Washington), that resulted in OLEDs that have more than $9 \%$ in external quantum efficiency. Novel phosphorescent polymers have been introduced and showed a promise in their application to OLEDs technology. These materials result in devices that have close to $10 \%$ in external quantum efficiency. Although this work, headed by G.C. Bazan (UCSB), is still in its early development stages, it indicates that polymers can indeed join small molecules in the race for the development of highly efficient OLEDs.

Addressing areas other than luminescence, T. Jackson (PSU) talked about the use of organic materials in TFT applications for electronics on flexible substrates; T. Swager (MIT) introduced new chemicals for sensor applications on the nanoscale; and a collaboration between P. Calvert and G.E. Jabbour (Univ. of Arizona) led to new avenues of using ink-jet printing techniques in the development of OLEDs and artificial muscles.

A joint session between Symposia P and $G$ featured Nobel Laureate A. Heeger (UCSB) who spoke on polymer LEDs and their role in plastic-based displays. Y. Si (Alien Technology) gave the firsttime demonstration of a polymer LED display driven by an integrated nano-

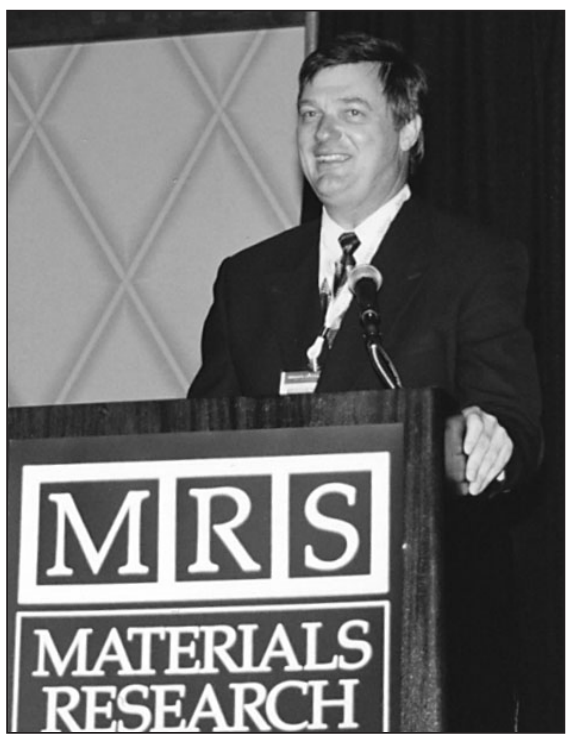

Jeff Wadsworth (Lawrence Livermore National Laboratory) gave the plenary address at the MRS Meeting in which he described the role of science and technology in counterterrorism. His talk was published in the May 2002 issue of MRS Bulletin, page 348.

block IC. Significant progress in the area of organic photovoltaics was also seen as evident. T. Martens (Limburgs Universitair Centrum, Belgium) discussed the influence of the microstructure upon the performance of a PV cell using organic polymers. N. Greenham (Cambridge) highlighted the spin-dependent recombination in PPV and polyfluorene-based LEDs.

Symposium Support: Eastman Kodak Co. and Universal Display Corp.

\section{The Dance of Organics and Inorganics Relies on Chemistry, Porosity, and Variety}

(See MRS Proceedings Volume 726)

Symposium $Q$ addressed the synthesis, characterization, and properties of organicinorganic hybrid materials. E.P. Giannelis (Cornell) set the tone for the Symposium with his description of how nanoparticles in polymer matrices can behave as random lasers, that is, lasers that do not exhibit coherence but still exhibit amplification by stimulated emission. D. Loy (SNL) gave a detailed overview of the chemistry and materials science of oligomerized silsesquioxane polymers as materials of use from patterning for electronics applications to materials for extracting heavy metals from waste streams. P. Hubert Mutin (Univ. of Montpellier) gave a related and detailed talk on phosphorus-based hybrids. U. Schubert (Technische Universitat of Vienna) gave a talk on the use of functionalized zirconium and titanium oxo clusters for forming highly cross-linked transparent nanocomposite materials with well-defined properties. B. Viers (ARL, Edwards AFB) provided an overview of work going on in the area of polyhedral oligomeric silsesquioxane materials and their value to the U.S. Air Force as hightemperature structural materials, especially for aerospace applications.

Several researchers presented topics on hybrid materials with a biomaterials flavor. Topics included statistical analysis of sol-gel process variables in producing biomaterials, the design of biocomposites for a variety of applications ranging from bonegrowth scaffolds, to "petrification" of wood, to studies by D. Morse (UCSB) on the use of biomethods for directing polymerization of silica and silsesquioxanes.

Another set of presentations explored the development of microporous materials using organic templates. S. Inagaki (Toyota) and J.J.E. Moreau (Ecole Nationale Superieure de Chimie) both described the use of templates in the polymerization of silsesquioxane to form highly novel porous structures for applications ranging from photonic devices to chiral porous materials potentially of value as novel separations media and catalyst supports. T. Bein (Univ. of Munich) reported on novel catalytic behavior in mesoporous materials. A. Stein (Univ. of Minnesota) used templating to generate porous zirconia photonic-bandgap materials wherein the size of the pores controlled the color of the light trapped and transmitted, giving a rainbow of materials. S. Stupp (Northwestern) demonstrated the use of designed templates for the selective crystallization and growth of hydroxyapatite fibers. R. Ryoo (KAIST) used templated growth to prepare porous carbon structures starting from templated silica materials.

A series of presentations focused on the development of new routes to hybrid materials and analytical procedures for delineating the exact nature of hybrid materials. P. Innocenzi (Univ. of Padova) discussed the use of FTIR to characterize mesoporous silica films. J.K. Balkus Jr. (Univ. of Texas, Dallas) discussed the formation of molecular-sieve materials in the form of fibers and films.

F. Babonneau (Paris VI) and P. Mirau (Lucent) discussed the use of various forms of multinuclear solid-state NMR for detailed characterization of nanostructured hybrid materials.

Several groups reported on physical properties found with hybrid materials. J. Zink (UCLA) and J.-P. Boilot (Paris VI) 
reported on electron transfer and photonic processes in hybrids. J-F. Gerard (INSA Lyon) reviewed the rheology and mechanical properties of selected hybrid materials.

\section{Theoreticians and Experimentalists Face Off about Nanostructured Materials \\ (See MRS Proceedings Volume 727)}

The purpose of Symposium R was to mix and connect theoreticians and experimentalists working on nanostructured materials for many different applications. Many speakers pointed out that the properties of nanostructured materials are always interface-controlled. The studies presented used state-of-the-art theoretical and experimental methods to investigate the structure-property relationship changes of materials with shrinking dimensions in one, two, or three directions. The presentations focused on how interface properties and interface engineering can be used to change macroscopic properties. Nanoparticles; quantum dots; nanowires, -tubes and -rods; and thin films were used for sensors, electronic and electro-optic devices, and for structural, magnetic, and catalytic systems.

Most of the experimental studies presented various TEM methods performed at the highest level, setting the state of the art for investigations at nanostructured interfaces. The challenging nature of those investigations was illustrated by M. Ruehle (MPI, Stuttgart). Another highlight was the quantitative comparison of calculated $a b$ initio structures to micrographs in which the accuracy was dramatically improved by using aberrationcorrected STEM, Z-contrast imaging, and the phase-reconstruction method. These atomic structure evaluations were complimented by surface techniques such as scanning probe analytic imaging or structuring (as shown by D. Bonnell, Univ. of Pennsylvania), scattering techniques such as XAS, and neutron or x-ray diffraction.

Many results of theoretical studies of nanostructured interfaces are still waiting for validation through experiments. Theoretical approaches for point-defect influences on nanostructures (e.g., W. Windl, OSU) and the influence of interfaces on nanoscale electronic devices (e.g., C. Roland, NCSU) clearly showed the recent advances in theory and the demand for applications of localized characterization techniques at nanostructured interfaces. However, not only investigations of solid and solid-liquid systems, but also the investigations of bioinspired and biorelated nanostructured systems showed that the influence of interfaces is the key for using such systems in devices.

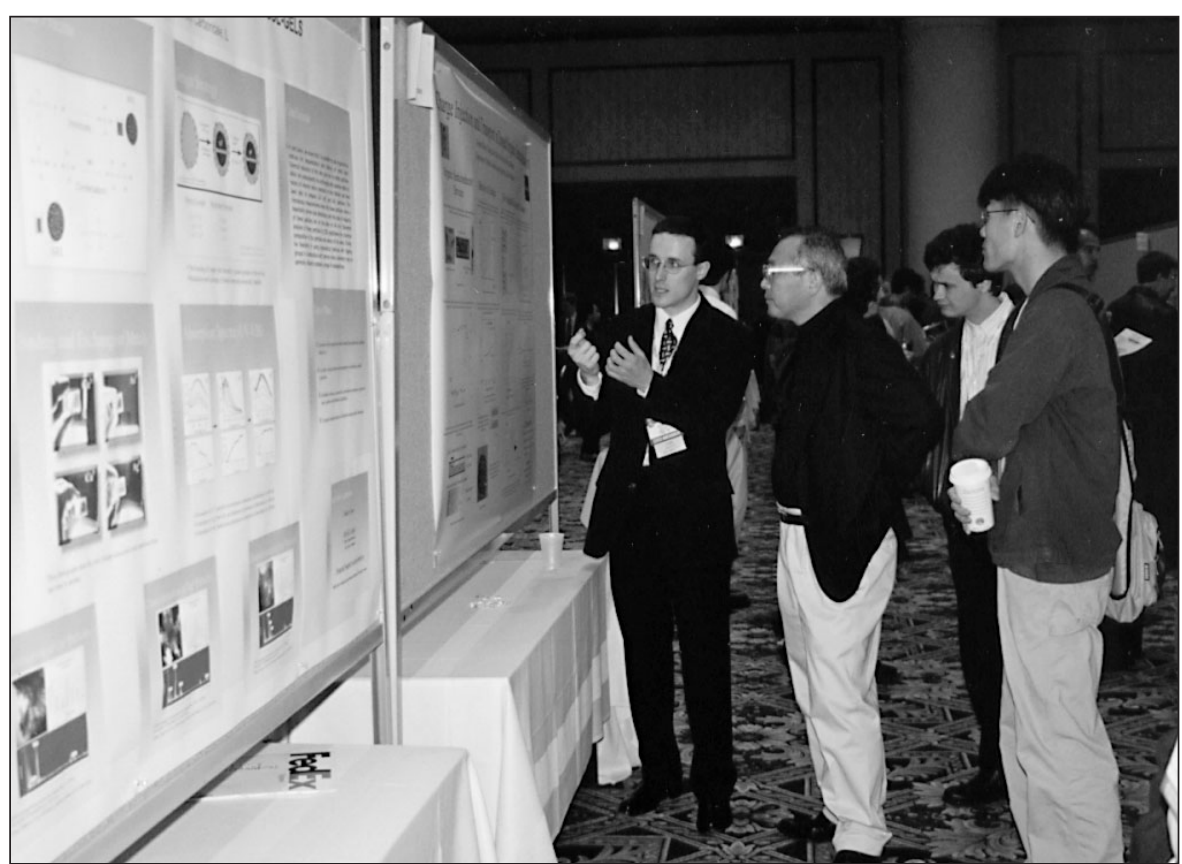

Poster Sessions held in the San Francisco Marriott and Argent Hotels covered $\sim 600$ presentations.

\section{Patterns and Arrays Form Backdrop of} Periodic Nanostructured Materials (See MRS Proceedings Volume 728)

Symposium $S$ covered a wide range of topics in the field of periodic nanoscale materials. The Symposium started with a session on the use of surfactant and polymer templating and inorganic/organic self-organization to produce nanoscale order. Topics in this area ranged from ceramic to bio-oriented composites and explored a diverse range of inorganic materials. The next session focused on novel methods for structural control and included topics as diverse as the use of proteins to control inorganic structure and high-temperature gas-phase reactions in which creativity was the key to complex structures. The focus moved to 2D structures, for example, surface patterning. There was a particular emphasis on the use of polymers to make complex patterns. The talks ranged from fundamental discussions of surface segregation and organization to applications of these patterns for functioning devices. A session on arrays of nanoscale wires showed how diverse chemistry could be used to produce a variety of materials with potential electronic and optical applications. Nanocrystal arrays were the focus of the next session, with a particular emphasis on the optical and electronic properties of these arrays. The emphasis then moved away from self-assembly with a session that explored how optical techniques can be used to encode information and produce structure on small length scales. The Symposium included a session that explored slightly larger length-scale arrays that have interesting photonic properties for controlling the propagation of light. A diverse range of materials, including colloids and bubbles, was organized using techniques ranging from templating and lithographic patterning to organization by electric fields. Overall, the Symposium showed the diverse range of options currently available for the production of nanoscale periodicity, and explored many of the exciting applications of these new materials.

\section{From Flame Retardancy to Longer Lasting Tennis Balls, Polymer Composites Show Their Strengths}

Symposium T illustrated the breadth of a new class of materials: polymer nanocomposites. Researchers reported the use of a great variety of inorganic materials, including clay minerals, vermiculites, and silsesquioxanes to carbon nanotubes and silver dendrimers, in making nanocomposites. The physical attributes of nanocomposites that were presented included flame retardancy, improved tensile strength and modulus without loss of impact resistance, lower permeability to gases, and improved electrical conductivity. The speakers also present- 
ed data on a host of both thermoplastics and thermoset polymers.

K. Kamena presented an overview of the commercial aspects of nanocomposites which is still an infant but shows great promise for the future. On the practical side, some speakers focused on processing of nanocomposites. L. James Lee (OSU) presented work on the use of supercritical $\mathrm{CO}_{2}$ for making nanocomposite foams and D.R. Paul (Univ. of Texas, Austin) focused on melt compounding of nylon- 6 to produce nanocomposites. Many pre- senters reported efforts to model these attributes with various simple models. Of note was one simple model reported by M.C. Boyce (MIT). This model did a very good job of predicting the change in modulus as a function of clay loading. A number of applications were presented of specific interest. The first reported by H.A. Goldberg (InMat LLC) was the new Wilson tennis ball that holds pressure twice as long by utilizing a coating on the inside of the balls composed of a butyl rubber nanocomposite. A second, reported
Biodegradable Polymers Microfabricated for Vascularized Tissue Engineering (See MRS Proceedings Volume 729)

Symposium U addressed various aspects of bioMEMS and MEMS materials and fabrication technology, as well as hybrid systems integration and methods of producing low-cost microfluidics and microactuators, combined with optical MEMS for optical communications or biomedical applications. A group from the MEMS Technology Group, Charles Stark Draper Laboratory and Center for Integration of Medicine and Innovative Technology (K. King, J. Borenstein, and J.P. Vacanti) described the application of advanced microfabrication technologies including silicon micromachining and polymer replica molding toward the field of tissue engineering of complex tissues and organs. As a general approach, tissue engineering of skin, bone, and cartilage using cell transplantation on biodegradable matrices has been successful. However, such techniques encounter difficulties when applied to complex tissues and vital organs. The principal limitation for such applications is the lack of an intrinsic blood supply for the tissue-engineered organ, which experiences significant cell death when the tissue thickness is increased above the $1-2-\mathrm{mm}$ range. In this work, the concept of microfabricated scaffolds is introduced, with the goal of producing organ templates with feature resolution of $1 \mu \mathrm{m}$, well in excess of that necessary to fashion the capillaries that comprise the microcirculation of the organ. Initial efforts have resulted in high-resolution biocompatible polymer scaffolds produced by replica molding from silicon micromachined template wafers (Figure 1). These scaffolds have been successfully seeded with endothelial cells in channels with dimensions as small as the capillaries (Figure 2).

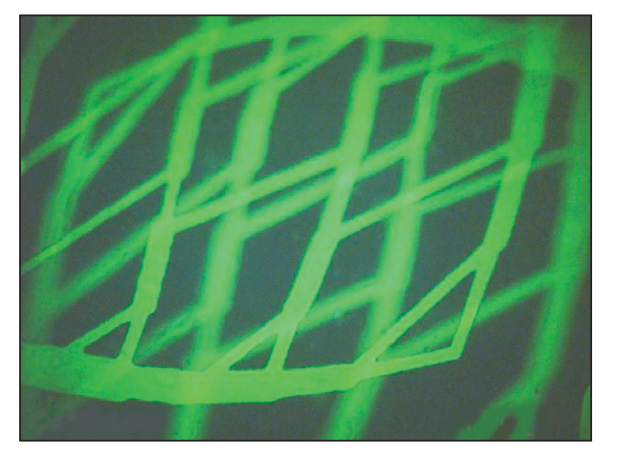

Figure 1. Multilayer microfluidic device constructed from biodegradable PLGA.

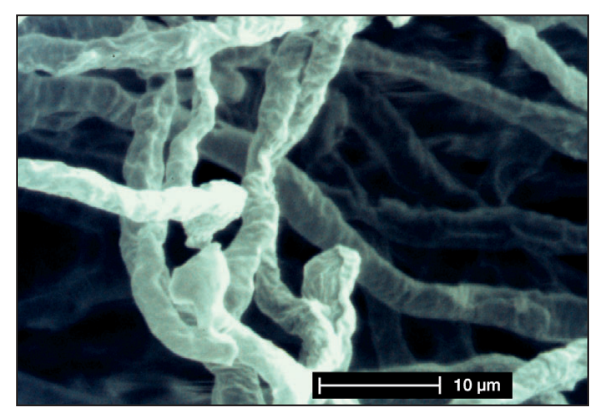

Figure 2. Successfully seeded with endothelial cells in channels with dimensions as small as the capillaries by using the microfabricated biodegradable PLGA scaffolds. by A.J. Hsieh (ARL), was of the improvement in ballistic behavior of polycarbonate laminated with a polycarbonate nanocomposite.

Symposium Support: AFRL Materials and Manufacturing Directorate, Merwyn C. Gill Foundation Composites Center, USC, and Southern Clay Products.

\section{Combined Modeling Methods Applied to Integrate Multiple Physical \\ Phenomena}

(See MRS Proceedings Volume 731)

In recent years, numerical simulation and modeling of materials coupling multiple length scales has received much attention. While many challenges remain, significant advances have been made in this area with a variety of techniques. An equally important area of materials modeling, one that has received much less attention, is the integration of multiple physical phenomena for simulation of complex materials behavior. Symposium $\mathrm{W}$ provided a forum to review the current capabilities in materials modeling and simulation that (1) bridge length scales and time scales, and (2) couple a variety of physical phenomena to either provide insight into fundamental aspects of materials structure or predict materials behavior. Presentations showed that the largest atomistic simulations are still in the billion atom range and cannot capture true materials behavior at the meso- or macroscale. A few clever techniques were presented such as bridging between atomistic simulations and continuum model by coupling a finite element method mesh around a molecular-dynamics simulation, or bridging between atomistic simulations and mesoscale models by renormalizing atoms to domains of many atoms in areas where less detail is necessary. However, the majority of current simulation techniques rely on parameter, constitutive relation, or statistical distribution passing from lower length and time scales to the coarser ones to bridge length scales. In contrast, there was a presentation on coupling physics to simulate complex materials behavior that truly did combine materials models. Some examples were of combining thermodynamic models with mechanical models to simulate microstructural evolution under mechanical stresses and simulation of ferroelectric response under mechanical loading by combining electric models with mechanical models.

Symposium Support: SNL. 